Post-print of Ercilla Montserrat, Mireia et al. «Building-integrated agriculture: a first assessment of aerobiological air quality in rooftop greenhouses (i-RTGs)» in Science of the Total Environment (ScienceDirect). Vol. 598 (November 2017), p. 109-120. The final version is available at DOI 10.1016/j.scitotenv.2017.04.099

\title{
Building-integrated agriculture: a first assessment of aerobiological air quality in
} rooftop greenhouses (i-RTGs)

Mireia Ercilla-Montserrat*1, Rebeca Izquierdo*2,3, Jordina Belmonte ${ }^{2,3}$, Juan Ignacio Montero ${ }^{4}$, Pere Muñoz ${ }^{4}$, Concepción De Linares ${ }^{2,3}$, Joan Rieradevall ${ }^{1,5}$ (*These authors contributed equally to the research.)

${ }^{1}$ Sostenipra Research Group (SGR 01412), Institute of Environmental Sciences and Technology (MDM-2015-0552), Z Building, Autonomous University of Barcelona (UAB), Campus UAB, 08193 Bellaterra, Barcelona, Spain

2 AEROBIOTA Research Group (2014SGR1274), Institute of Environmental Sciences and Technology (ICTA), Z Building, Universitat Autònoma de Barcelona (UAB), Campus UAB, 08193 Bellaterra, Barcelona, Spain

3 Departament de Biologia Animal, Biologia Vegetal i Ecologia, Universitat Autònoma de Barcelona (UAB). Edifici C, 08193 Bellaterra, Spain

${ }^{4}$ Institute of Food and Agricultural Research (IRTA), Carretera de Cabrils, km 2, 08348 Barcelona, Spain

${ }^{5}$ Department of Chemical, Biological and Environmental Engineering, School of Engineering, Building Q, Universitat Autònoma de Barcelona (UAB), 08193 Bellaterra, Barcelona, Spain.

Corresponding author: Mireia Ercilla-Montserrat. Sostenipra Group. Institut de Ciència i Tecnologia Ambientals, ICTA ICTA-ICP, Edifici Z - Despatx Z/139 Carrer de les columnes Universitat Autònoma de Barcelona. E- 08193 Bellaterra (Cerdanyola del Vallès - Barcelona). Tel: (+34) 935868645. E-mail address: Mireia.ercilla@uab.cat

Key words: urban agriculture, greenhouse, tomato crop, pollen grains, fungal spores, indoor and outdoor bioaerosols, air recirculation, symbiosis

\begin{abstract}
Building-integrated rooftop greenhouse (i-RTG) agriculture has intensified in recent years, due to the growing interest in the development of new agricultural spaces and in the promotion of food self-sufficiency in urban areas. This paper provides a first assessment of the indoor dynamics of bioaerosols in an i-RTG, with the aim of evaluating biological air quality in a tomato greenhouse near Barcelona. It evaluates the greenhouse workers' exposure to airborne pollen and fungal spores in order to prevent allergy problems associated with occupational tasks. Moreover, it evaluates whether the quality of the hot air accumulated in the i-RTG is adequate for recirculation to heat the building.
\end{abstract}

Daily airborne pollen and fungal spore concentrations were measured simultaneously in the indoor and outdoor environments during the warm season. A total of 4,924 pollen grains were observed in the i-RTG, with a peak of 334 pollen grains $/ \mathrm{m}^{3} \mathrm{day}$, and a total of 295,038 fungal spores were observed, reaching a maximum concentration of 26,185 spores $/ \mathrm{m}^{3} \mathrm{day}$. In general, the results showed that the most important source of pollen grains and fungal spores observed indoors was the outdoor environment. However, Solanaceae pollen and several fungal spore taxa, such as the allergenic Aspergillus/Penicillium, largely originated inside the greenhouses or were able to colonize the indoor environment under favourable growing conditions. Specific meteorological conditions and agricultural management tasks are related to the highest observed indoor concentrations of pollen grains and fungal spores. Therefore, preventive measures have been suggested in order to reduce or control the levels of bioaerosols indoors (to install a system to interrupt the recirculation of air to the building during critical periods or to implement appropriate air filters in ventilation air ducts). This first evaluation could help in making 
46 decisions to prevent the development of fungal diseases, specifically those due to Oidium and 47 Torula.

\section{INTRODUCTION}

49 Urban agriculture, particularly rooftop urban agriculture, has increased in the last few years. 50 This is due to the coupled needs of encouraging food sovereignty in urban areas and providing a 51 response to the growing competition for resources associated with conventional agriculture 52 (water, energy, land, etc.) (FAO, 2011). It is thought that the global food system causes between $5320 \%$ and $50 \%$ of total global anthropogenic pressure (directly or indirectly). Most of this 54 pressure is attributable to cities, due to the many people who live there.

55 Currently, different types of urban agriculture have been developed in urban areas (Fig. 1). 56 Rooftop urban agriculture (RT) is a subcategory within this concept that includes all those crop 57 plants grown on the tops of buildings. RT not only makes it possible to produce food, it also 58 provides environmental and social benefits to surrounding areas. These benefits include 59 boosting local urban markets; making use of empty constructed spaces; creating new sources of 60 employment and support for local economies; allowing savings on the transport of goods and 61 packaging materials; increasing urban biodiversity and naturalizing the environment; etc. 62 (Altieri et al., 1999; Cerón-Palma et al., 2012; Sanyé-Mengual et al., 2013; Specht et al., 2014). 63 RT can be carried out both outdoors and in sheltered environments, which have become known 64 as rooftop greenhouses (Despommier, 2008). 
67 Figure 1. Typologies and nomenclatures used to describe urban agriculture on buildings and 68 rooftop farming

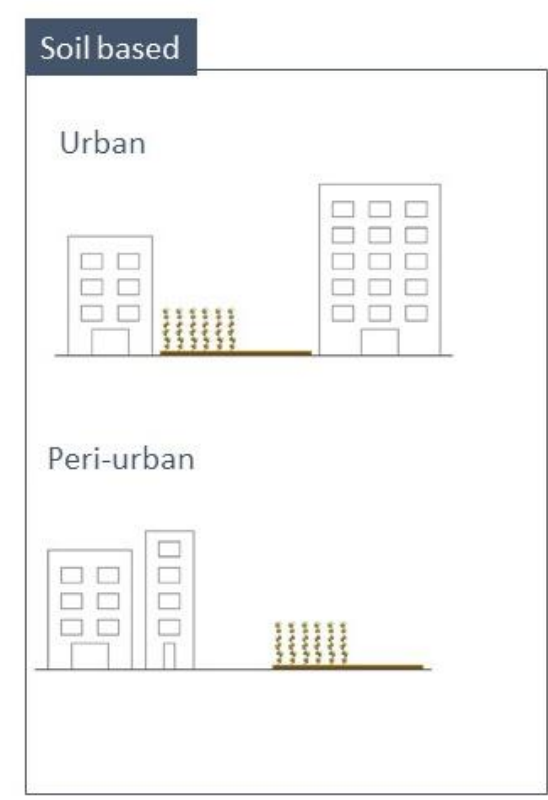

\section{Building-based}

\section{Indoor farming}

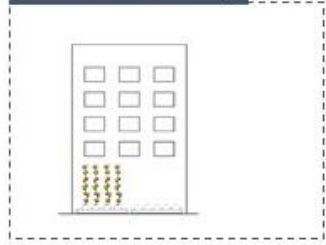

Vertical farming

Skyfarming

Edible walls
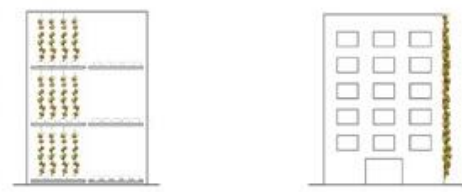

Rooftop farming

Open air

Greenhouse i-RTG

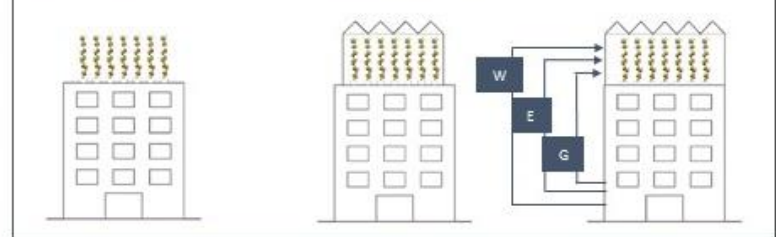

i-RTG integrated rooftop

greenhouse

W Rainwater

E Waste energy

G GHG emissions

Rooftop greenhouses and the first steps toward integrated rooftop greenhouses

Rooftop greenhouses consist of greenhouses installed on top of buildings to produce food in urban contexts with high yield using soil-free growing systems (to reduce the structural load on the building). They increase the efficiency of resource use and employ constructed spaces that are currently unoccupied (Cerón-Palma et al., 2012). Many of the existing experiments involve greenhouses constructed on roofs that are isolated from the buildings. However, this kind of RT greenhouse can also be integrated (i-RTG) into the building, using residual air flows from the building for the crops (Cerón-Palma, 2012). 
energy. This is true because, first, due to their particular features, i-RTGs provide thermal insulation on the roof of the building. Second, they offer the possibility of supplying air from heated/air conditioned areas to the crops using a pumping system.

Greenhouses used for intensive cultivation of horticultural crops also use the carbon enrichment technique known as carbon fertilization to improve yield. In an i-RTG, this technique consists of increasing the environmental level of $\mathrm{CO}_{2}$ by injecting waste $\mathrm{CO}_{2}$ from offices and laboratories inside the building via an air current. Exposure to environments with a high concentration of carbon dioxide generally stimulate crop growth and photosynthetic fixation (i.e., in the case of tomatoes exposed to a $\mathrm{CO}_{2}$ concentration of $900 \mu \mathrm{mol} \cdot \mathrm{m}^{-3}$, the rate of growth increased by $30 \%$ ) (Yelle et al., 1990).

Meanwhile, they also offer the possibility of using greywater or rainwater collected in or on the building for irrigating the crop (Montero et al., 2009).

A new study has recently begun investigating the possibility of creating two-way connections between a building and its greenhouses. Such a greenhouse is known as a bidirectional integrated rooftop greenhouse (Bi-RTG) (Fig. 2). These greenhouses would, among other things, make it possible to use the residual hot air accumulated in the greenhouses, which needs to be ventilated, to heat other areas of the building that do not have a heating system. Previously, the heat was removed by opening the flap ventilators of the greenhouse. The location of the greenhouses on the roofs of buildings promotes higher temperatures inside the greenhouse than in the rest of the building. This occurs because the greenhouse acts as a solar collector and heats up with the incidence of solar radiation through the polycarbonate cover during the day. It does not occur with the same rapidity in the building, which has more thermal inertia and receives less radiation. It enables improving the environmental thermic conditions of the building with minimal energetic and environmental impact.

Figure 2. The bidirectional Bi-RTG concept behind the i-RTG Lab. The exchange of flows between the ICTA-ICP building and the i-RTG is shown.

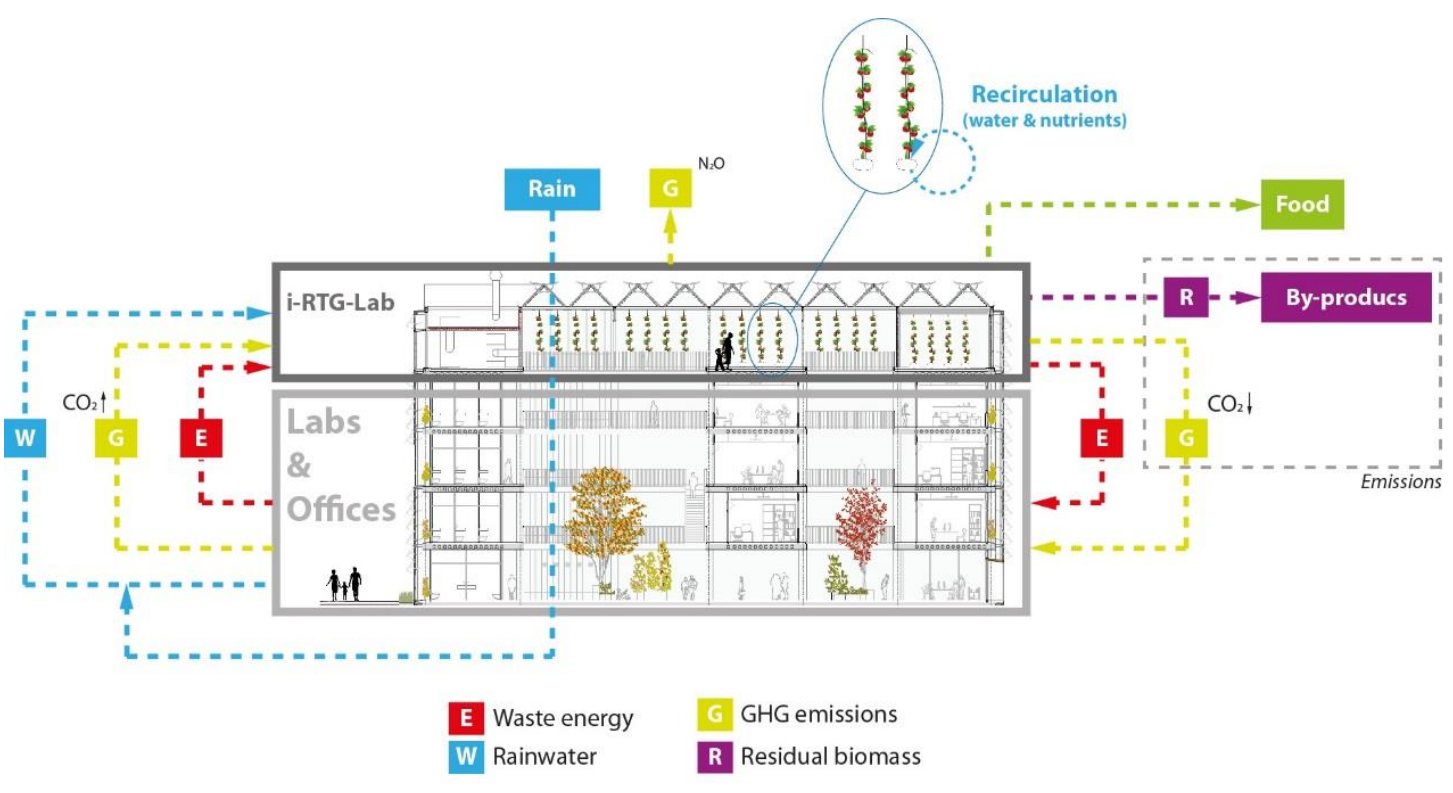


It is important to evaluate the air quality in these greenhouses, due to the ability of the Bi-RTG system to draw air from the crop area into the building spaces. With regard to the $\mathrm{CO}_{2}$ concentration, the situation is convenient because the $\mathrm{CO}_{2}$ is absorbed by the crop, improving the air quality. However, the biological air quality (pollen and fungal spore concentrations) must be studied and taken into account to avoid causing or aggravating allergies and breathing problems, both in terms of the use of the air for space heating and to protect the health of the agricultural workers, who spend large amounts of time inside the greenhouses.

\section{Air quality in greenhouses}

It is known that agricultural greenhouse workers are exposed to dust particles suspended in the air. This dust contains bioaerosols, such as spores and pollen, which can cause respiratory problems. These problems include chronic bronchitis, allergies and/or "sensitization and hypersensitivity pneumonitis" (Illing, 1997; Taekhee Lee et al., 2006a; Swan and Crook, 1998) and asthma (Malling et al., 1986; Strachan, 1988).

The conditions of these working environments are characterized by closed spaces, high temperatures, high humidity and high concentrations of microorganisms in the environment. These microclimatic characteristics encourage the growth of fungi and the consequent dispersal of spores (Arny and Rowe, 1991; Jewett et al., 2001). Moreover, restricted ventilation and low light intensity, especially on the bottoms of the plants, are common. This situation is very conducive to the development of several plant diseases, and controlling them is very difficult (Elad et al., 1995).

Exposure levels vary depending on the type of crop, the tasks carried out and the season of the year. The most important periods when pollution occurs are when the plants are senescent, and the pollution is aggravated if the greenhouse is not properly maintained (removing dry leaves, sweeping passageways, etc.) (Hansen et al., 2011).

Most of the vegetable and ornamental plants grown in greenhouses suffer from powdery mildew. Powdery mildew affects all kind of plants, except gymnosperms, and is one of the most common and widespread plant diseases (Agrios, 2005). On tomato crops, the most important fungi causing this disease are Oidium sp (Elad et al., 1996). Powdery mildews are characterized by grey or white sporulation colonies on the upper leaf surface. The inoculum consists mostly of conidia. Once infection occurs, it develops rapidly under dry conditions. Dry climates favour dispersal of spores, while humid climates favour spore germination (Agrios, 2005). This is because conidia spores are self-sufficient in terms of water and nutrients and can germinate, grow and infect plants without dew or condensation (Verhaar, 1998).

\section{Air quality inside buildings}

In the case of buildings, the situation is different, as they are fairly isolated from the external environment, and the concentrations of pollen and spores detected inside buildings are usually lower than those found outside (Nayar and Jothish, 2013). However, the outside air often continues to be the dominant source of biological pollution inside buildings; therefore, indoor air quality can be interpreted via careful study of the external air (Dassonville et al., 2008; Ghosh et al., n.d.; Shelton et al., 2002). The concentrations detected inside are related to the ventilation of the building and the air conditioning (Flores et al., 2014; Shelton et al., 2002), the opening or closing of windows and doors and the flow of people (Abdulla et al., 2008; Bastl et 
al., 2016; D'Amato et al., 1996; Jantunen and Saarinen, 2009; Buss et al. ,2010). Some studies carried out inside buildings point out that allergies persist after the pollination period. Air quality inside a building is a key factor because of the potential health effects, as it is estimated that people spend $80 \%$ of their time inside buildings every week (Cariñanos et al., 2004)

The assessment of fungal exposure is complex, considering that fungi are ubiquitous microorganisms that are present in both outdoor and indoor air. There are two main sources of fungal spores in buildings: outdoor sources, which leak rain into or cause flooding in the building, and indoor sources, which are derived from human activity or accidents that cause water damage (Bornehag et al., 2004). Common outdoor fungi include Alternaria, Cladosporium, and Epicoccum, as well as ascospores and basidiospores, though these fungi are often found indoors because they enter through open doors and windows and can be carried indoors (Levetin et al., 2016). Fungi that are more classically associated with indoor water damage or decay include Penicillium, Aspergillus, Stachybotrys, and Chaetomium (Levetin et al., 2016). In the case of fungal spores, the indoor-outdoor relationship has not been systematically studied, and most of the available information is based on the simultaneous measurement of culturable fungal spores performed indoors and outdoors (Lee et al., 2006) or on comparisons of the diversity and number of fungal colonies in university classrooms before and during the presence of the students (Buss et al., 2010). However, the total spore count has shown a better exposure to response relationship compared to the culture-based method (Eduard, 2003). Therefore, continuous sampling and spore counting could have a greater potential to generate an adequate database.

European Union legislation currently excludes the monitoring of the concentrations of pollen and spores because they are not considered a consequence of human activity, and Brussels does not compel member States to compile this information. As there are no regulations on this matter, certain limitations as to assessing air quality inside buildings exist (Immunology, 2015)

Current reference values of spore concentrations include those from the American Conference of Governmental Industrial Hygienists (ACGIH 1999), which sets a threshold of $200 \mathrm{CFU} / \mathrm{m}^{3}$, and Health Canada (Nathanson, 1993), which gives a figure of $150 \mathrm{CFU} / \mathrm{m}^{3}$. These guidelines recommend that concentrations inside buildings should be no greater than those outside. Although the threshold concentrations required to trigger allergic reactions are unknown, Eduard (2009) suggests that the lowest observed effective level for the appearance of respiratory symptoms for diverse fungal species is $10^{5} \mathrm{spores} / \mathrm{m}^{3}$ per day in non-sensitised populations, while (Santilli and Rockwell, 2003a) consider that the standard for a healthy indoor environment should be defined as $10^{3}$ spores $/ \mathrm{m}^{3}$ per day.

The goals of this study are as follows:

1. To determine airborne pollen and fungal spore spectra indoors (inside an i-RTG) and outdoors in order to identify the diversity, daily concentrations and frequency of each taxon during the cultivation of a tomato crop inside the facility and in the semi-urban area where it is placed, using the same aerobiological monitoring method.

2. To determine the influence of indoor and outdoor meteorological conditions and crop management practices on the biological air quality in the i-RTG.

3. To assess the greenhouse workers' exposure to airborne pollen and fungal spores in order to prevent allergy problems derived from occupational tasks. 
4. To evaluate whether the quality of the hot air accumulated in the i-RTG is adequate for reuse inside the building, and to assess the risk of causing or aggravating respiratory problems.

5. To identify critical stages of the crop production process, and to develop preventive measures to avoid exposing agricultural greenhouse workers and building users to noxious substances if the air is used to heat the building.

\section{MATERIAL AND METHODS}

\section{i-RTG Greenhouse Laboratory}

The investigation was conducted in a rooftop greenhouse laboratory (the i-RTG Lab) during an experiment involving growing tomatoes (Solanum lycopersicum Arawak). The i-RTG is placed on the rooftop of the building hosting the Institute of Environmental Science and Technology (ICTA-UAB) and the Catalan Institute of Paleontology (ICP) at Bellaterra (41 ${ }^{\circ} 23^{\prime} 40.03^{\prime \prime} \mathrm{N}, 2^{\circ}$ 9'50.76"E). The building is on the campus of the Universitat Autònoma de Barcelona, which lies $10 \mathrm{~km}$ northwest of Barcelona (Catalonia, Spain). Although the campus is located in a highly populated area between two highways with high volumes of traffic, the university's facilities are surrounded by a forested landscape (Fig. 2). The i-RTG Lab (Fig. 3) is the case study of the "Fertilecity" project ${ }_{(1)}$. Overall, it covers an area of $125 \mathrm{~m}^{2}$, and part of this area $\left(84,34 \mathrm{~m}^{2}\right)$ supports a crop including 171 tomato plants grown in a perlite media. The winter planting was carried out on the $15^{\text {th }}$ of September 2016, and the growing season lasted 167 days. The winter crop was planted on the $8^{\text {th }}$ of March, and the growing season was 139 days. The purpose of building the i-RTG Lab was to demonstrate the feasibility of RTGs in Mediterranean urban zones and the potential for their symbiosis with buildings to optimize the efficiency of both the buildings and the greenhouses efficiency (including heating using residual hot air from the RTG, using the increased $\mathrm{CO}_{2}$ concentration in the building air as a fertilizer in the RTG, and by collecting rainwater from the rooftop for the irrigation system). The water and the nutrient solution needed by the plants were provided through a drip fertirrigation system. Five control schedules administer heating, cooling and window openings to optimize energy use. Each control schedule adjusts the greenhouse control system to adapt it to seasonal temperature requirements (Nadal et al., 2017). Three different ventilation modes were applied in the i-RTG during this study: (1) the winter mode was employed from the $24^{\text {th }}$ of February to the $31^{\text {st }}$ of March 2016 ( $\mathrm{N}$ days=37), (2) the spring mode was employed from the $1^{\text {st }}$ of March to the $31^{\text {st }}$ of May $2016(\mathrm{~N}$ days $=60)$ and (3) the summer mode was employed from the $1^{\text {st }}$ of June to the $28^{\text {th }}$ of July 2016 ( $\mathrm{N}$ days=60); the highest ventilation rate occurred during the summer mode and the lowest occurred during the winter mode. 
231 Figure 3. Probe locations within the i-RTG and in the surrounding area.

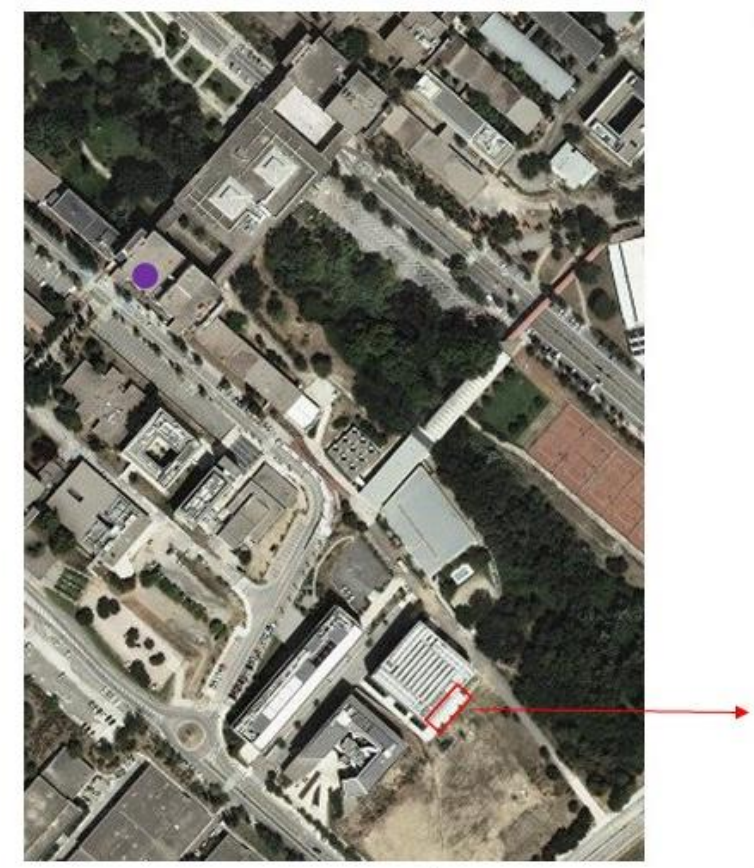

Orthophoto $1: 5,000(50 \mathrm{~cm} / \mathrm{px})$

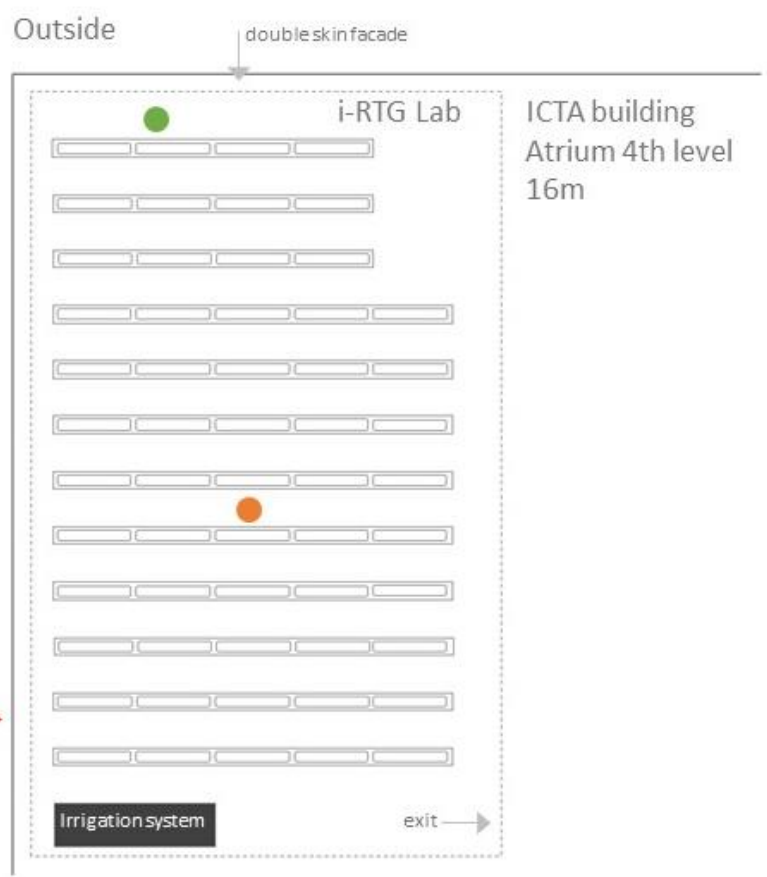

Indoor aerobiological monitoring
i-RTG Lab $16 \mathrm{~m}$

- Outdoor aerobiological monitoring $30 \mathrm{~m}$

Indoor T, HR monitoring

\section{Airborne pollen and fungal spore sampling}

234

235

Simultaneous daily i-RTG indoor and outdoor aerobiological monitoring was conducted to test the air quality. The methodology used is standard for outdoor measurements (Hirst, 1952) and represents an innovation in the study of air quality in greenhouses.

According to the Spanish Aerobiology Network working protocol (Galán et al., 2007), the outdoor aerobiological sampler was placed on top of the UAB-C building at 30 m.a.s.l. The indoor sampler was located in the i-RTG Lab, which is $150 \mathrm{~m}$ away from the $\mathrm{C}$ building.

Samples were obtained using volumetric suction pollen-spore traps based on the impact principle (Hirst, 1952), which is the standard method in European aerobiological networks (Galán et al., 2014). The Hirst sampler is calibrated to handle a continuous flow of $10 \mathrm{~L}$ of air per minute, thus matching the human breathing rate. Pollen and spores impact a cylindrical drum covered with Melinex film (Melinex tape, LANZONI s.r.l., Bologna, IT) film and coated with a $2 \%$ silicone solution as the trapping surface. The drum is located over a mechanism that causes it to rotate clock at a speed of $2 \mathrm{~mm} /$ hour. The exposed tape surface sample was changed weekly at a known time and was cut into one piece per day ( 0 to $24 \mathrm{~h}$ GMT), which was mounted on microscopic slides. Pollen and fungal spore identification was performed by technicians specializing in palynology using a light microscope at 600X magnification, based on morphological characteristics and counting. Daily average pollen concentrations were calculated following the standardized Spanish method (Galán et al., 2007), which consists of analysing 
four continuous longitudinal sweeps. Spores were analysed along one continuous longitudinal sweep. Daily pollen and fungal spore concentrations were expressed as the number of pollen grains and spores per cubic metre of air. Finally, the sum and maximum of daily pollen/fungal spore concentrations were used to calculate the indoor/outdoor ratio (hereafter $\mathrm{i} / \mathrm{o}_{\text {sum }}$ ratio and $\mathrm{i} / \mathrm{o}_{\max }$ ratio, respectively).

\section{Study period}

The sampling period extended from the $10^{\text {th }}$ of April 2016 to the $28^{\text {th }}$ of July 2016, but the sample analyses were divided into two phases, depending on the intensity of the analyses. Phase I (which extended from the $24^{\text {th }}$ of February to the $10^{\text {th }}$ of April 2016), which coincided with the last month of the winter crop and the initiation of the leaf growth, flowering and fruiting stages of the summer crop was conducted, considering both pollen and fungal spores. Phase II (which extended from the $11^{\text {th }}$ of April to the $28^{\text {th }}$ of July 2016), which included the entire summer crop cycle, was mainly devoted to fungal spores (during the entire period) and to Solanaceae pollen (during the removal of the summer crop, which lasted from the $20^{\text {th }}$ to the $28^{\text {th }}$ of July 2016). This period coincides with the hottest months, when the connection between the greenhouse and the outside is more pronounced. As a result, our study also evaluated the aerobiological air quality in the RTG during the critical period characterized by the greatest degree of outdoor influence.

\section{Indoor and outdoor environmental variables}

Indoor temperature and relative humidity were monitored in the i-RTG during the sampling period to determine the effects of environmental conditions on the pollen and fungal spore dynamics. TwoCampbell SCI CS215-Lsensors were used to record the temperature and relative humidity inside the greenhouse. To collect data from the Campbell devices, a CR3000 datalogger was used. The i-RTG Lab has a mechanism to open and close the ventilation system depending on internal and external temperatures, allowing passive acclimatization and ventilation.

The possible influence of plant and fungi phenological stages, agricultural pest incidence, crop treatments and greenhouse maintenance services on indoor aerobiological data were also taken into account as indoor variables. After the growing season, the plants were removed, the long plant stems and support strings were cut down, and they were then bundled together in the aisles. Thereafter, the plants were packaged in industrial garbage bags and transported outside.

Outdoor daily mean temperature, relative humidity, precipitation and wind speed were obtained from the Sant Cugat del Vallès meteorological station (41 $\left.28^{\prime} 59.2^{\prime \prime} \mathrm{N} 2^{\circ} 04^{\prime} 46.4 " \mathrm{E}\right)$ belonging to the Catalan Meteorological Service, which was located near the outdoor pollen-spore trap, were used as outdoor variables.

\section{Statistical analysis}

Spearman's non-parametric correlation test has been used to explore the relationships between: (1) indoor (inside the i-RTG) vs. outdoor daily pollen and fungal spore concentrations; (2) all the indoor and outdoor environmental variables between them; (3) the indoor aerobiological data vs. the indoor variables; and (4) the outdoor aerobiological data vs. the outdoor meteorological variables. Spearman's rank correlation coefficients (rho) were considered to be 
significant when the p-values were $<0.05$. The statistical analyses were performed using Statistica ${ }^{\mathrm{TM}}$.

\section{RESULTS}

\section{Airborne pollen diversity and dynamics}

297

298

299

300

301

302

303

304

305

306

307

308

309

310

311

In the first part of this paper, we discuss the results of daily airborne pollen concentrations registered indoors and outdoors during phase I, which extended from the $24^{\text {th }}$ of February to the $10^{\text {th }}$ of April 2016. Considering the whole dataset ( $\mathrm{n}=47$ daily samples), 47 pollen types were identified. 33 pollen taxa were identified in the indoor environment, and 45 were identified outdoors (see Table 1, Fig. 4). Taxa that were represented by more than 10 indoor pollen grains represented $98 \%$ of the total indoor pollen and $97 \%$ of the total outdoor. According to this criterion, 17 pollen taxa were selected to study the indoor-outdoor relationship in detail: Acer, Alnus, Cupressaceae, Fraxinus, Morus, Pinus, Platanus, Populus, Quercus deciduous type, Quercus evergreen type, Salix, Ulmus, Coriaria, Corylus, Mercurialis, Urticaceae and Solanaceae.

Figure 4. Daily Solanaceae airborne pollen concentrations recorded in the i-RTG during phase I of this study (which extended from the $24^{\text {th }}$ of February to the $10^{\text {th }}$ of April 2016) and the last stage of the summer tomato crop (which extended from the $20^{\text {th }}$ of July to the $28^{\text {th }}$ of July 2016) in phase II. The initiation of the leaf growth, flowering and fruiting stages are shown. Crop removal (CR) stages are highlighted for both the winter and summer tomato crops.

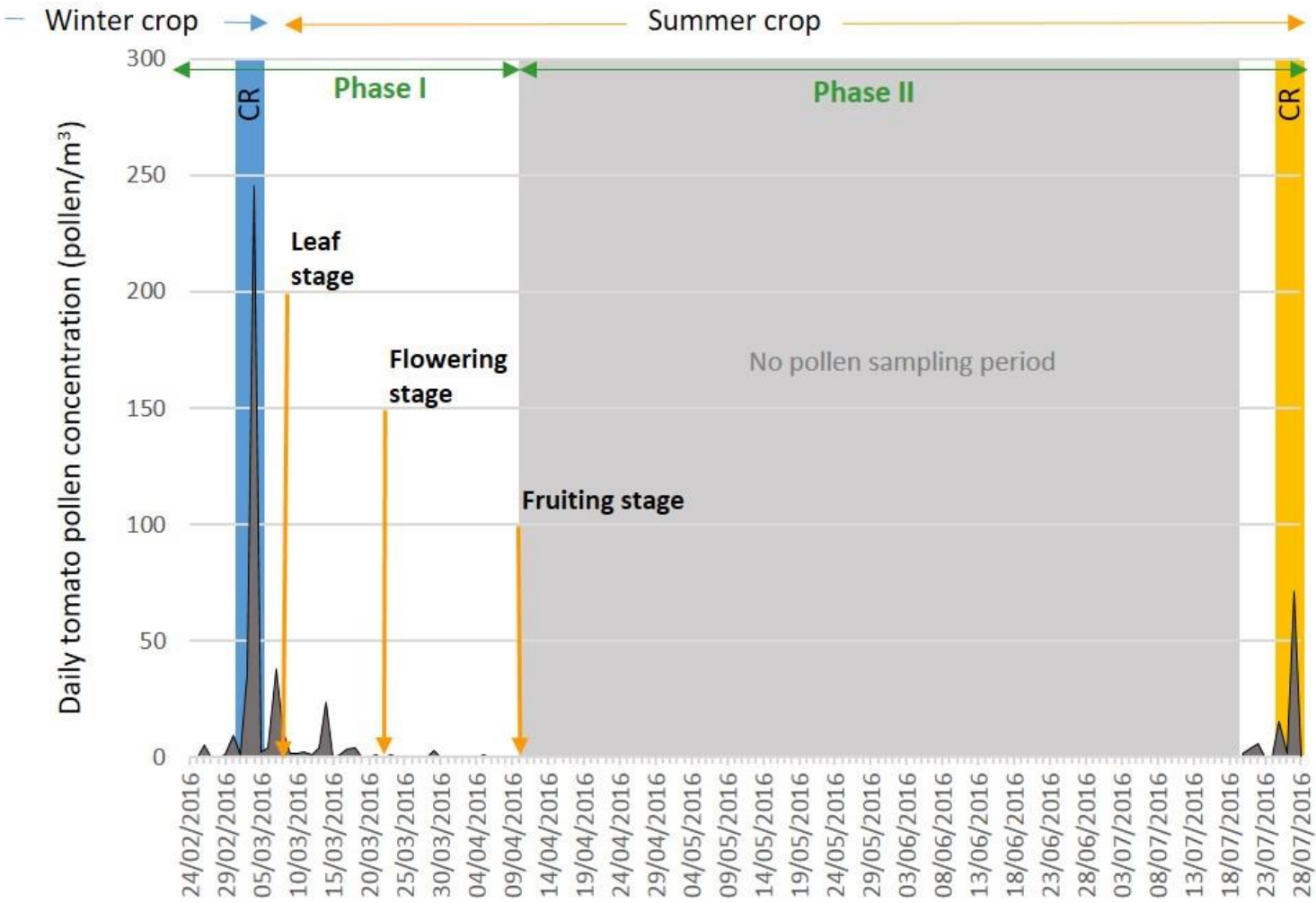

Table 1 shows an overview of the results for the selected pollen taxa and the relationship between the concentrations indoors, in the i-RTG, and the outdoor concentrations. A total of 4,924 pollen grains were counted and identified in the indoor environment versus 17,132 outdoors. The maximum daily concentrations were 334 pollen grains $/ \mathrm{m}^{3}$, which was observed 
317 indoors on the $4^{\text {th }}$ of March 2016, and 932 grains $/ \mathrm{m}^{3}$, which was observed outdoors on the $27^{\text {th }}$ 318 of March 2016 (Table 1). The most abundant pollen taxon in both environments was Platanus, 319 the pollen sum of which accounted for 1,751 pollen grains indoors and 5,051 outdoors, and its 320 maximum daily concentration was 179 pollen grains $/ \mathrm{m}^{3}$, which was observed indoors on the $32130^{\text {th }}$ of March 2016 and 460, which was observed outdoors on the $27^{\text {th }}$ of March 2016 (Table 1). 322 The second taxon was Pinus, the pollen sum of which ranged between 1,095 and 4,526 pollen 323 grains, and the maximum daily concentrations were 98 pollen grains $/ \mathrm{m}^{3}$, which was observed 324 indoors on the $28^{\text {th }}$ of March 2016, and 319, which was observed outdoors on the $5^{\text {th }}$ of March 3252016 (Table 1). Platanus and Pinus accounted for 56 and 58\% of the total pollen in both the 326 indoor and outdoor environments, respectively.

327 Solanaceae is the only pollen taxon that was detected exclusively in the indoor environment. 328 Solanaceae was the third most abundant taxon in the indoor environment, with a total of 399 329 pollen grains ( $8 \%$ of indoor total pollen) and a peak concentration of 246 pollen grains $/ \mathrm{m}^{3}$ was 330 observed on the $4^{\text {th }}$ of March 2016 when winter crop removal was carried out (Fig. 4). This 331 concentration was the highest daily pollen concentration recorded in the i-RTG (Table 1). Two 332 other peak concentrations of Solanaceae pollen were observed between the winter crop removal 333 stage and the initiation of the flowering stage, which accounted for 38 pollen grains $/ \mathrm{m}^{3}$ on the $3347^{\text {th }}$ of March 2016 and 24 pollen grains $/ \mathrm{m}^{3}$ on the $14^{\text {th }}$ of March 2016. Finally, high 335 concentrations of Solanaceae pollen were also measured on the $27^{\text {th }}$ of July 2016 during the 336 summer crop removal, accounting for 71 pollen grains $/ \mathrm{m}^{3}$ (Fig. 4). The i/o ratio and Spearman's 337 rank correlation analysis were not applicable.

338 The $\mathrm{i} / \mathrm{o}_{\text {sum }}$ ratio was 0.11 for total pollen during the phase I sampling period. This quantity 339 ranged between 0.02 and 0.17 for the different pollen taxa, whereas the $\mathrm{i} / \mathrm{o}_{\max }$ ratio was 0.36 and 340 ranged between 0.04 and 1.07. Ulmus was the only taxon with an $\mathrm{i} / \mathrm{o}_{\max }$ ratio $>1$ (Table 1 ). 341 Positive and significant correlations between the indoor and outdoor concentrations were 342 observed in 14 cases out of 16 (Table 1). 
345 Table 1. Spectra of pollen taxa: (1) mean, maximum and sum of daily pollen concentrations 346 (pollen grains $/ \mathrm{m}^{3}$ ) recorded in both indoor and outdoor environments from the $24^{\text {th }}$ of February 347 to the $10^{\text {th }}$ of April $2016(\mathrm{~N}$ days $=47)$; (2) indoor/outdoor (i/o) ratio of using the maximum

\begin{tabular}{|c|c|c|c|c|c|c|c|c|c|c|}
\hline \multirow{2}{*}{\multicolumn{2}{|c|}{ Pollen taxa }} & \multicolumn{3}{|c|}{ Indoor } & \multicolumn{3}{|c|}{ Outdoor } & \multicolumn{2}{|c|}{ i/o ratio } & \multirow{2}{*}{$\begin{array}{l}\text { Spearman's } \\
\text { rank } \\
\text { correlation }\end{array}$} \\
\hline & & Mean & Max & Sum & Mean & $\operatorname{Max}$ & Sum & $\mathbf{i} / \mathbf{o}_{\max }$ & $\mathrm{i} / \mathbf{o}_{\text {sum }}$ & \\
\hline \multirow{12}{*}{ Trees } & Acer & 1.4 & 16.8 & 65.1 & 3.0 & 26.6 & 140.0 & 0.63 & 0.05 & $0.76^{*}$ \\
\hline & Alnus & 0.3 & 2.1 & 14.0 & 1.4 & 14.0 & 65.1 & 0.15 & 0.02 & $0.44 *$ \\
\hline & Cupressaceae & 15.1 & 102.9 & 711.2 & 56.0 & 346.5 & $2,632.7$ & 0.30 & 0.04 & $0.66^{*}$ \\
\hline & Fraxinus & 0.3 & 2.8 & 15.4 & 1.4 & 7.7 & 65.8 & 0.36 & 0.04 & $0.33 *$ \\
\hline & Morus & 3.5 & 23.1 & 162.4 & 16.1 & 98.0 & 755.3 & 0.24 & 0.04 & $0.78^{*}$ \\
\hline & Pinus & 23.3 & 98.0 & $1,094.8$ & 96.3 & 319.2 & $4,526.2$ & 0.31 & 0.07 & $0.61 *$ \\
\hline & Platanus & 37.3 & 179.2 & $1,751.4$ & 107.5 & 459.9 & $5,050.5$ & 0.39 & 0.08 & $0.88 *$ \\
\hline & Populus & 5.3 & 25.9 & 249.2 & 44.9 & 217.7 & $2,111.9$ & 0.12 & 0.02 & $0.46^{*}$ \\
\hline & $\begin{array}{l}\text { Quercus deciduous } \\
\text { type }\end{array}$ & 2.1 & 18.9 & 100.8 & 14.3 & 128.1 & 672.0 & 0.15 & 0.02 & $0.78 *$ \\
\hline & $\begin{array}{l}\text { Quercus evergreen } \\
\text { type }\end{array}$ & 0.2 & 3.5 & 10.5 & 0.5 & 7.0 & 22.4 & 0.50 & 0.03 & 0.25 \\
\hline & Salix & 0.7 & 7.0 & 33.6 & 1.0 & 9.1 & 48.3 & 0.77 & 0.08 & $0.32 *$ \\
\hline & Ulmus & 1.4 & 11.2 & 65.8 & 2.7 & 10.5 & 128.8 & 1.07 & 0.13 & $0.50 *$ \\
\hline
\end{tabular}

$348\left(\mathrm{i} / \mathrm{o}_{\max }\right)$ and the total $\left(\mathrm{i} / \mathrm{o}_{\text {sum }}\right)$ values; and (3) Spearman's rank correlation coefficient (rho) values 349 between the indoor and outdoor daily pollen concentrations. 


\begin{tabular}{|c|c|c|c|c|c|c|c|c|c|c|}
\hline \multirow{2}{*}{ Shrubs } & Coriaria & 0.2 & 2.1 & 11.2 & 0.7 & 5.6 & 32.2 & 0.38 & 0.04 & $0.42 *$ \\
\hline & Corylus & 0.4 & 2.8 & 18.2 & 1.6 & 9.1 & 77.0 & 0.31 & 0.04 & 0.26 \\
\hline \multirow{3}{*}{$\begin{array}{l}\text { Herbaceous } \\
\text { plants }\end{array}$} & Mercurialis & 0.7 & 3.5 & 30.8 & 2.2 & 7.7 & 102.2 & 0.45 & 0.09 & $0.32 *$ \\
\hline & Urticaceae & 2.3 & 14.7 & 107.1 & 4.5 & 16.1 & 213.5 & 0.91 & 0.14 & $0.46^{*}$ \\
\hline & Solanaceae & 8.5 & 245.7 & 399.0 & 0.0 & 0.0 & 0.0 & - & - & - \\
\hline \multicolumn{2}{|c|}{ Other pollen taxa $^{1}$} & 1.8 & 6.3 & 83.3 & 10.4 & 154.7 & 488.6 & 0.04 & 0.17 & $0.37 *$ \\
\hline \multicolumn{2}{|l|}{ Total pollen } & 104.8 & 333.9 & $4,923.8$ & 364.5 & 931.7 & $17,132.5$ & 0.36 & 0.11 & $0.65^{*}$ \\
\hline
\end{tabular}

$350 \quad{ }^{1}$ less than 10 pollen grains during the sampling period 351 


\section{Airborne fungal spore diversity and dynamics}

354 Fungal spore dynamics recorded during the whole sampling period (phases I and II, which 355 extended from the $24^{\text {th }}$ of February to the $28^{\text {th }}$ of July 2016) are analysed in detail in the second 356 part of this paper. The diversity of fungal spores observed included 29 taxa in the indoor 357 environment versus 31 outdoors. Taxa that accounted for more than 10 indoor fungal spores 358 during the study period accounted for $99.9 \%$ of the total spores in both environments. 359 Considering this threshold, 26 fungal spore taxa were selected: Agaricus, Agrocybe, Alternaria, 360 Arthrinium, Aspergillus/Penicillium, Chaetomium, Cladosporium, Coprinaceae, 361 Drechslera/Helminthosporium, Epicoccum, Ganoderma, Leptosphaeria, Myxomycota, Oidium, 362 Pithomyces, Pleospora, Polythrincium, Stemphyllium, Thelephoraceae, Torula, Ustilago, 363 Xylariaceae, other ascospores (unicellular, bicellular, pluricellular) and other basidiospores.

364 A total of 295,039 fungal spores were identified from the indoor environment and 606,642 from 365 the outdoor environment were identified during the study period (Table 2). The maximum daily 366 concentration of total fungal spores observed indoors was 26,186 spores $/ \mathrm{m}^{3}$ on the $27^{\text {th }}$ of July 3672016 during the summer ventilation mode, and 28,000 spores $/ \mathrm{m}^{3}$ was observed outdoors on the $36810^{\text {th }}$ of May 2016 during the spring mode (Table 2, Fig. 5a). The most abundant fungal spore 369 taxa in the indoor environment (where the total was $>10,000$ spores and the maximum was > 3703000 spores $/ \mathrm{m}^{3}$ ) were Cladosporium (129,234 spores), the group of other ascospores (15,27737194,822 spores) and Aspergillus/Penicillum (10,055 spores); followed by Ustilago, Coprinaceae, 372 Alternaria, Agrocybe and Oidium, for which the total over the period ranged between 1,000 and 37310,000 spores (Table 2). The totals of the rest of the taxa accounted for $<1,000$ spores during the 374 study period (Table 2). 
Figure 5. Indoor (inside the i-RTG) and outdoor variations in: (a) daily fungal spore concentrations of Cladosporium and total spores; (b) daily precipitation and mean temperature and mean relative humidity, from the $24^{\text {th }}$ of February to the $28^{\text {th }}$ of July 2016 . Ventilation modes are also indicated.

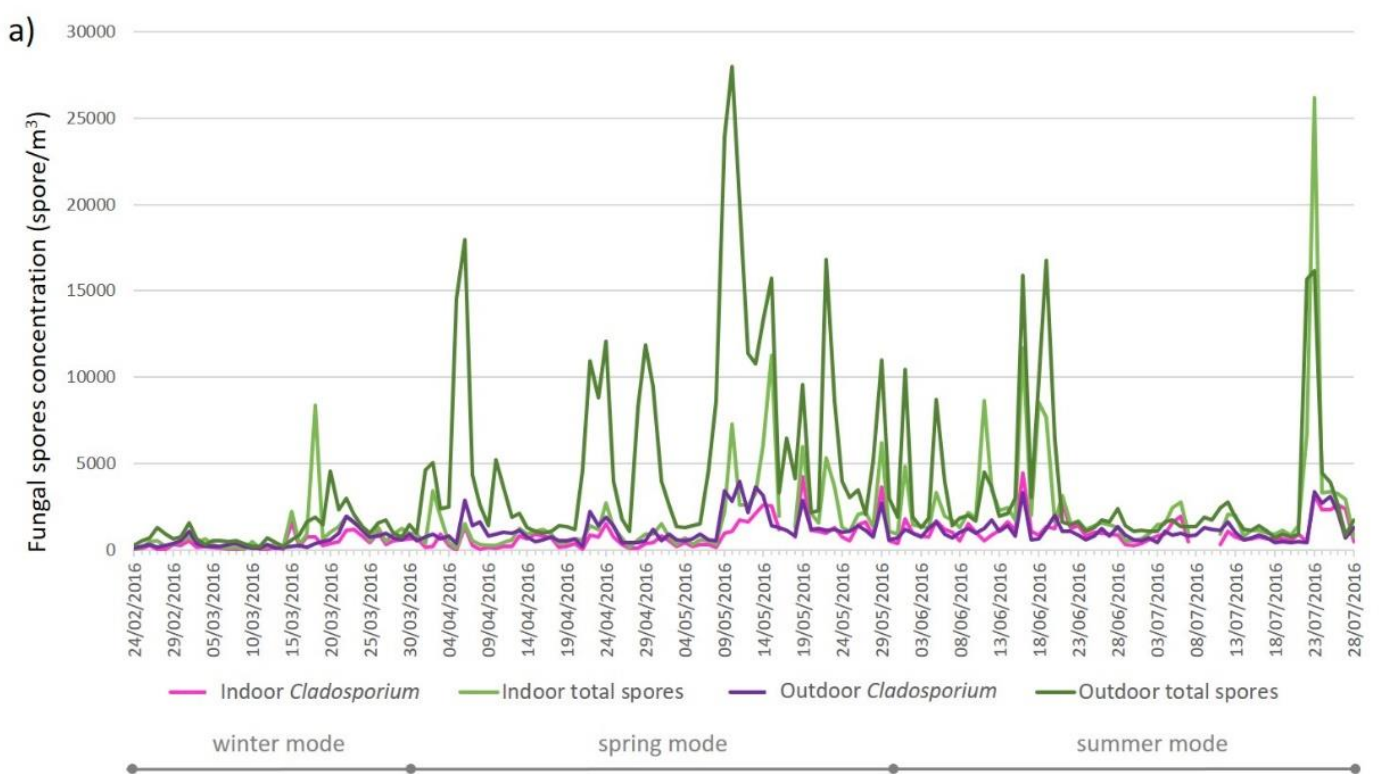

b)
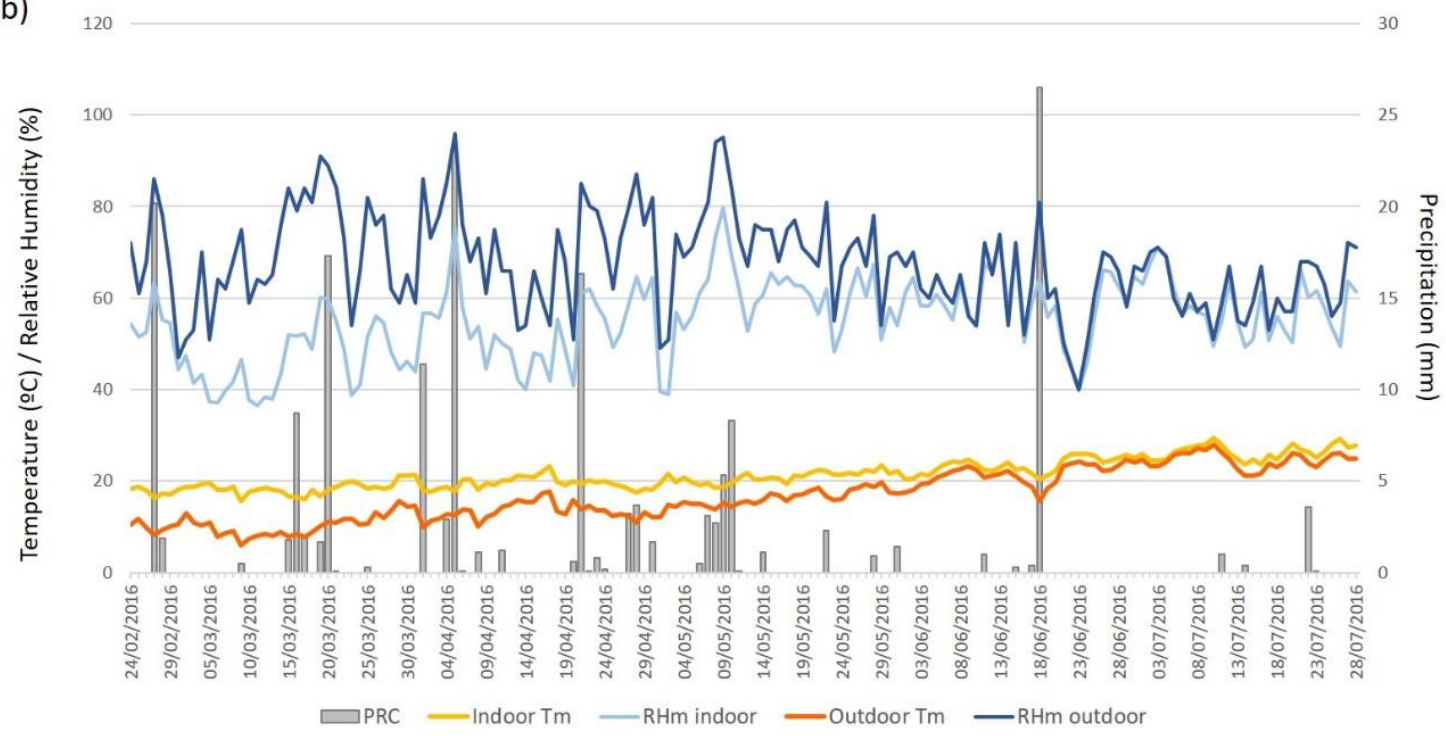

In the outdoor environment, more than 10,000 spores were recorded for Cladosporium $(154,314$ spores) and the group of other ascopores (33,396-327,827 spores) during the study period; however, Aspergillus/Penicillum accounted for 4,281 spores (Table 2). Excluding Aspergillus/Penicillum, fungal spore taxa that ranged between 1,000-10,000 spores outdoors were, in decreasing order, Coprinaceae, Ustilago, Alternaria, Agrocybe, Ganoderma, Pleospora and Oidium (Table 2). The totals of the rest of the taxa accounted for $<1,000$ spores during the study period (Table 2 ).

Based on the i/o ratios, the fungal spore taxa were classified into three groups: (1) $\mathrm{i} / \mathrm{o}_{\text {sum }}$ and i/omax ratios $\leq 1$ were observed for Agaricus, Agrocybe, Chaetomium, Coprinaceae, Epicoccum, Ganoderma, Leptosphaeria, Pleospora, Stemphyllum, Thelephoraceae, Xylariaceae, other ascospores (unicellular, pluricellular), other basidiospores and total fungal spores during the 

417

whole study period and the spring ventilation mode; (2) $\mathrm{i} / \mathrm{o}_{\text {sum }}$ ratio $\leq 1$ and $\mathrm{i} / \mathrm{o}_{\max }$ ratio $>1$ for Alternaria, Arthrinium, Cladosporium, Oidium, Polythrincium, Ustilago, the other bicelullar ascospores and the total fungal spores during the winter and summer ventilation modes; and (3) $\mathrm{i} / \mathrm{o}_{\text {sum }}$ and $\mathrm{i} / \mathrm{o}_{\max }$ ratios $>1$ for Aspergillus/Penicillum, Drechslera/Helminthosporium, Myxomycota, Pithomyces, Torula and other basidiospores (Table 2). The case of Aspergillus/Penicillum should be highlighted; it showed an $\mathrm{i} / \mathrm{o}_{\max }$ ratio of 28 , given that its maximum daily concentration indoors was 6986 spores $/ \mathrm{m}^{3}$ versus 252 outdoors (Table 2).

Positive and significant correlations were observed for 17 fungal spore taxa out of 26 , as well as the total fungal spores for the whole period and the three ventilation modes (Table 2). The strongest correlations between data from indoors (inside the i-RTG) and outdoors (rho >0.60; pvalue $<0.05$ ) were observed for Alternaria, Cladosporium, Coprinaceae, Ustilago, Ganoderma and other ascopores (bicellular, pluricellular), as well as for the total fungal spores during the winter and summer ventilation modes. The indoor and outdoor dynamics of the daily fungal spore concentrations of Cladosporium and total spores are shown in Fig. 5a. No correlations were observed between indoor and outdoor daily concentrations for 9 taxa. Note that the indoor and outdoor dynamics were independent for Agaricus, Aspergillus/Penicillium, Chaetomium, Epicoccum, Myxomycota, Oidium, Pithomyces, Polythrincium and Torula.

Table 2. Spectra of fungal spore taxa: (1) mean, maximum and sum of daily fungal spore concentrations (spores $/ \mathrm{m}^{3}$ ) recorded in both indoor (inside the i-RTG) and outdoor environments during the whole sampling period (from the $24^{\text {th }}$ of February to the $28^{\text {th }}$ of July $2016, \mathrm{~N}$ days $=152$ ); (2) i/o ratio of the maximum (i/o $\mathrm{o}_{\max }$ ) and the total (i/o $\left.\mathrm{o}_{\text {sum }}\right)$; and (3) Spearman's rank correlation coefficient (rho) between indoor and outdoor daily fungal spores concentrations. In addition, these data were calculated for total fungal spores during the periods corresponding to the different ventilation modes: winter (from the $24^{\text {th }}$ of February to the $31^{\text {st }}$ of March 2016, N days = 37), spring (from the $1^{\text {st }}$ of March to the $31^{\text {st }}$ of May 2016, $\mathrm{N}$ days $=60$ ) and summer (from the $1^{\text {st }}$ of June to the $28^{\text {th }}$ of July $2016, \mathrm{~N}$ days $=60$ ).

\begin{tabular}{|c|c|c|c|c|c|c|c|c|c|}
\hline \multirow{2}{*}{ Fungal spore taxa } & \multicolumn{3}{|c|}{ Indoor } & \multicolumn{3}{|c|}{ Outdoor } & \multicolumn{2}{|c|}{ i/o ratio } & \multirow{2}{*}{$\begin{array}{l}\text { Spearman's } \\
\text { rank } \\
\text { correlation }\end{array}$} \\
\hline & Mean & Max & Sum & Mean & Max & Sum & $\mathrm{i} / \mathrm{o}_{\max }$ & $\mathbf{i} / \mathbf{o}_{\text {sum }}$ & \\
\hline Agaricus & 3.4 & 22.4 & 518.0 & 5.6 & 44.8 & 854.0 & 0.50 & 0.61 & 0.14 \\
\hline Agrocybe & 7.3 & 47.6 & $1,106.0$ & 16.2 & 81.2 & $2,464.0$ & 0.59 & 0.45 & $0.46^{*}$ \\
\hline Alternaria & 22.6 & 182.0 & $3,432.8$ & 24.2 & 179.2 & $3,670.8$ & 1.02 & 0.94 & $0.70^{*}$ \\
\hline Arthrinium & 4.9 & 291.2 & 747.6 & 5.0 & 78.4 & 753.2 & 3.71 & 0.99 & $0.29 *$ \\
\hline Aspergillus/Penicillium & 66.2 & $6,986.0$ & $10,054.8$ & 28.2 & 252.0 & $4,281.2$ & 27.72 & 2.35 & 0.01 \\
\hline Chaetomium & 0.1 & 2.8 & 14.0 & 0.3 & 2.8 & 39.2 & 1.00 & 0.36 & -0.06 \\
\hline Cladosporium & 850.2 & $4,449.2$ & $129,234.0$ & $1,015.2$ & $3,956.4$ & $154,313.6$ & 1.12 & 0.84 & $0.69 *$ \\
\hline Coprinaceae & 28.0 & 266.0 & $4,253.2$ & 47.5 & 431.2 & 7218.4 & 0.62 & 0.59 & $0.64 *$ \\
\hline Drechslera/Helminthosporium & 3.2 & 33.6 & 492.8 & 2.0 & 16.8 & 310.8 & 2.00 & 1.59 & $0.45^{*}$ \\
\hline Epicoccum & 1.9 & 14.0 & 285.6 & 1.9 & 22.4 & 288.4 & 0.63 & 0.99 & 0.11 \\
\hline Ganoderma & 6.2 & 50.4 & 935.2 & 11.6 & 67.2 & $1,755.6$ & 0.75 & 0.53 & $0.64 *$ \\
\hline Leptosphaeria & 0.7 & 11.2 & 106.4 & 2.3 & 78.4 & 347.2 & 0.14 & 0.31 & $0.24^{*}$ \\
\hline Myxomycota & 0.1 & 14.0 & 16.8 & 0.1 & 11.2 & 14.0 & 1.25 & 1.20 & -0.01 \\
\hline Oidium & 7.1 & 89.6 & $1,080.8$ & 7.2 & 42.0 & $1,100.4$ & 2.13 & 0.98 & 0.15 \\
\hline Pithomyces & 0.1 & 2.8 & 14.0 & 0.1 & 2.8 & 11.2 & 1.00 & 1.25 & -0.03 \\
\hline Pleospora & 3.9 & 89.6 & 588.0 & 7.3 & 92.4 & $1,106.0$ & 0.97 & 0.53 & $0.36^{*}$ \\
\hline Polythrincium & 0.4 & 11.2 & 61.6 & 0.4 & 5.6 & 64.4 & 2.00 & 0.96 & 0.01 \\
\hline Stemphyllium & 1.9 & 25.2 & 291.2 & 2.4 & 25.2 & 358.4 & 1.00 & 0.81 & $0.26^{*}$ \\
\hline Thelephoraceae & 1.7 & 14.0 & 263.2 & 3.7 & 33.6 & 565.6 & 0.42 & 0.47 & $0.40^{*}$ \\
\hline Torula & 1.9 & 39.2 & 294.0 & 1.8 & 53.2 & 266.0 & 0.74 & 1.11 & 0.13 \\
\hline Ustilago & 35.8 & 450.8 & $5,437.6$ & 44.9 & 229.6 & $6,820.8$ & 1.96 & 0.80 & $0.66^{*}$ \\
\hline
\end{tabular}




\begin{tabular}{|c|c|c|c|c|c|c|c|c|c|}
\hline Xylariaceae & 3.8 & 25.2 & 582.4 & 4.7 & 39.2 & 714.0 & 0.64 & 0.82 & $0.44^{*}$ \\
\hline Other unicellular ascospores & 623.8 & $13,834.8$ & $94,822.0$ & $2,156.8$ & $19,107.2$ & $327,826.8$ & 0.72 & 0.29 & $0.41^{*}$ \\
\hline Other bicellular ascospores & 100.5 & $5,474.0$ & $15,276.8$ & 219.7 & $3,494.4$ & $33,395.6$ & 1.57 & 0.46 & $0.62^{*}$ \\
\hline Other pluricellular ascospores & 157.9 & $3,245.2$ & $24,007.2$ & 375.4 & $5,684.0$ & $57,061.2$ & 0.57 & 0.42 & $0.74^{*}$ \\
\hline Other basidiospores & 5.4 & 64.4 & 817.6 & 4.8 & 30.8 & 725.2 & 2.09 & 1.13 & $0.39 *$ \\
\hline Other fungal spores taxa ${ }^{1}$ & 0.1 & 2.8 & 16.8 & 0.4 & 14.0 & 53.2 & 0.20 & 0.32 & 0.07 \\
\hline Total fungal spores & $1,941.0$ & $26,185.6$ & $295,038.8$ & $3,991.1$ & $28,000.0$ & $606,642.4$ & 0.94 & 0.49 & 0.58* \\
\hline Total fungal spores - winter & 874.0 & $8,388.8$ & $32,337.2$ & $1,085.8$ & $4,558.4$ & $40,174.4$ & 1.84 & 0.80 & $0.75^{*}$ \\
\hline Total fungal spores - spring & $1,767.1$ & $11,244.8$ & $106,027.6$ & $6,311.2$ & $28,000.0$ & $378,669.2$ & 0.40 & 0.28 & $0.51^{*}$ \\
\hline Total fungal spores - summer & $2,848.6$ & $26,185.6$ & $156,674.0$ & $3,414.5$ & $16,744.0$ & $187,798.8$ & 1.56 & 0.83 & $0.73^{*}$ \\
\hline
\end{tabular}

$418{ }^{1}$ less than 10 fungal spores during the sampling period $\quad *$ p-value $<0.05$

419

420 Effects of environmental variables on airborne fungal spore levels

421 Strong significant positive correlations were observed between indoor $v s$. outdoor temperatures

$422($ rho $=0.96, \mathrm{p}$-value $<0.05)$ and relative humidity ( $\mathrm{rho}=0.55$, $\mathrm{p}$-value $<0.05)$ (Table 3$)$. However,

423 temperature values were higher indoors, in the i-RTG, than outdoors, and relative humidity was

424 higher outdoors (Fig. 2b). Temperature and relative humidity indoors (inside the i-RTG)

425 showed a weak significant positive correlation ( $\mathrm{rho}=0.21$, $\mathrm{p}$-value $<0.05$ ), however, a stronger

426 significant negative correlation was observed outdoors (rho=-0.43; p-value <0.05) (Table 3, Fig.

4275 b). Outdoor relative humidity was also strongly positively correlated with precipitation (rho=-

4280.59 , p-value $<0.05$; Fig. 5b) and negatively with wind speed (rho=-0.59; p-value <0.05) (Table

429 3). In the same way, precipitation also showed weak significant negative relationships with

430 outdoor temperature (rho=-0.29; p-value <0.05) and wind speed (rho=-0.33; p-value <0.05)

431 (Table 3).

432 Table 3. Spearman's rank correlations between indoor and outdoor environmental daily data from the $43324^{\text {th }}$ of February to the $28^{\text {th }}$ of July $2016(\mathrm{~N}$ days $=152)$ : mean temperature $\left(\mathrm{T}_{\mathrm{m}}\right)$, mean relative humidity $434\left(\mathrm{RH}_{\mathrm{m}}\right)$, precipitation (PRC) and mean wind speed $\left(\mathrm{WS}_{\mathrm{m}}\right)$.

435

\begin{tabular}{|l|l|r|r||r|r|r|r|}
\hline \multirow{2}{*}{$\begin{array}{l}\text { Spearman's rank } \\
\text { correlations }\end{array}$} & \multicolumn{2}{|c||}{ Indoor variables } & \multicolumn{4}{|c|}{ Outdoor variables } \\
\cline { 2 - 8 } & $\mathbf{T}_{\mathbf{m}}\left({ }^{\circ} \mathrm{C}\right)$ & $\mathbf{R H}_{\mathbf{m}}(\%)$ & $\mathbf{T}_{\mathbf{m}}\left({ }^{\circ} \mathrm{C}\right)$ & $\mathbf{R H}_{\mathbf{m}}(\%)$ & $\mathbf{P}(\mathrm{mm})$ & $\mathbf{W S}_{\mathrm{m}}(\mathrm{m} / \mathrm{s})$ \\
\hline \multirow{2}{*}{$\begin{array}{l}\text { Indoor } \\
\text { variables }\end{array}$} & $\mathbf{T}_{\mathbf{m}}\left({ }^{\circ} \mathrm{C}\right)$ & 1.00 & $0.21^{*}$ & $0.96^{*}$ & $-0.52^{*}$ & $-0.36^{*}$ & $0.22^{*}$ \\
\hline \hline \multirow{2}{*}{$\begin{array}{l}\text { Outdoor } \\
\text { variables }\end{array}$} & $\mathbf{R H}_{\mathbf{m}}(\%)$ & & 1.00 & $0.37^{*}$ & $0.55^{*}$ & $0.31^{*}$ & $-0.36^{*}$ \\
\cline { 2 - 8 } & $\mathbf{T}_{\mathbf{m}}\left({ }^{\circ} \mathrm{C}\right)$ & & & 1.00 & $-0.43^{*}$ & $-0.29^{*}$ & 0.14 \\
\cline { 2 - 8 } & $\mathbf{R H}(\%)$ & & & & 1.00 & $0.59^{*}$ & $-0.59^{*}$ \\
\cline { 2 - 8 } & $\mathbf{P}(\mathrm{mm})$ & & & & & 1.00 & $-0.33^{*}$ \\
\cline { 2 - 7 }$(\mathrm{m} / \mathrm{s})$ & & & & & & 1.00 \\
\hline
\end{tabular}

$*$ p-value $<0.05$ 
440 The relationship between fungal spore concentrations and environmental variables was explored 441 in Table 4. Indoors (inside the i-RTG), daily concentrations of the total fungal spores and 11 out of 26 taxa were positively and significantly correlated with both indoor temperature and relative 443 humidity. These 11 taxa were Agaricus, Alternaria, Cladosporium, 444 Drechslera/Helminthosporium, Ganoderma, Pithomyces, Torula, Ustilago, Xylariaceae, other ascospores (bicellular, pluricellular) and other basidiospores. Arthrinium, Oidium, Epicoccum and Stemphyllium were also positively correlated, but only with indoor temperature; Coprinaceae and Leptosphaeria were positively correlated exclusively with indoor relative humidity. The strongest correlations ( $r h o \geq 0.50 ; \mathrm{p}$-value $<0.05)$ were observed between the indoor temperature and Alternaria, Ganoderma, other basidiospores and total fungal spores.

Outdoor total fungal spores showed significant positive correlations with outdoor temperature, relative humidity and precipitation (Table 4). Depending on the fungal spore taxon, both positive and negative significant correlations were observed for each outdoor variable. Outdoor temperature was correlated with 16 fungal spore taxa. (1) It was positively correlated with Agaricus, Alternaria, Arthrinium, Cladosporium, Drechslera/Helminthosporium, Epicoccum, Ganoderma, Oidium, Stemphyllium, Torula, Ustilago, Xylariaceae, and other basidiospores; and (2) it was negatively correlated with Agrocybe, Aspergillus/Penicillium and Pleospora. Outdoor relative humidity was significantly correlated with 13 taxa. (1) It was positively correlated with Agrocybe, Leptosphaeria, Pleospora and other ascospores (unicellular, bicellular, pluricellular); and (2) it was negatively correlated with Alternaria, Epicoccum, Ganoderma, Oidium, Stemphyllium, Ustilago and other basidiospores. Precipitation showed a significant relationship with 10 outdoor taxa. (1) It was positively correlated with Leptosphaeria, Pleospora and other ascospores (unicellular, bicellular, pluricellular); and (2) it was negatively correlated with Alternaria, Chaetomium, Epicoccum, Ganoderma, and Torula. Finally, wind speed presented weak significant correlations with 4 taxa: (1) positively with Alternaria and Epicoccum; and (2) negatively with Xylariaceae and other unicellular ascospores. Alternaria and Ganoderma showed the strongest correlations with both indoor and outdoor temperature (rho ranged from 0.68 to $0.75 ; \mathrm{p}$-value $<0.05$ ). Strong correlations (with rho $\geq 0.50$ and $\mathrm{p}$-value $<0.05$ ) were observed for outdoor temperature vs. Alternaria, Ganoderma, Ustilago and other basidiospores, as well as for precipitation $v s$. other ascospores (bicellular, pluricellular).

Table 4. Spearman's rank correlations (rho) between daily: (1) indoor (inside the i-RTG) fungal spore concentrations $\left(\right.$ spore $\left./ \mathrm{m}^{3}\right)$ vs. indoor mean temperature $\left(\mathrm{T}_{\mathrm{m}}\right)$ and mean relative humidity $\left(\mathrm{RH}_{\mathrm{m}}\right)$; and (2) outdoor fungal spore concentrations (spore $/ \mathrm{m}^{3}$ ) vs. outdoor $\mathrm{T}_{\mathrm{m}}, \mathrm{RH}_{\mathrm{m}}$, precipitation $(\mathrm{P})$ and mean wind speed $\left(\mathrm{WS}_{\mathrm{m}}\right)$ from the $24^{\text {th }}$ of February to the $10^{\text {th }}$ of April $2016(\mathrm{~N}$ days $=152)$.

\begin{tabular}{|l||r|r||r|r|r|r||}
\hline $\begin{array}{l}\text { Spearman's } \\
\text { correlations }\end{array}$ & \multicolumn{2}{|c||}{ Indoor variables } & \multicolumn{4}{c|}{ Outdoor variables } \\
\hline Fungal spore taxa & $\mathbf{T}_{\mathbf{m}}\left({ }^{\circ} \mathrm{C}\right)$ & $\mathbf{R H}_{\mathbf{m}}(\%)$ & $\mathbf{T}_{\mathbf{m}}\left({ }^{\circ} \mathrm{C}\right)$ & $\mathbf{R H}_{\mathbf{m}}(\%)$ & $\mathbf{P}(\mathrm{mm})$ & $\mathbf{W S}(\mathrm{m} / \mathrm{s})$ \\
\hline Agaricus & $0.21^{*}$ & $0.29^{*}$ & $0.18^{*}$ & 0.05 & -0.02 & -0.06 \\
\hline Agrocybe & 0.01 & $0.28^{*}$ & $-0.18^{*}$ & $0.33^{*}$ & 0.12 & -0.15 \\
\hline Alternaria & $0.69^{*}$ & $0.27^{*}$ & $0.68^{*}$ & $-0.35^{*}$ & $-0.25^{*}$ & $0.25^{*}$ \\
\hline Arthrinium & $0.34^{*}$ & 0.14 & $0.26^{*}$ & -0.10 & -0.15 & 0.01 \\
\hline Aspergillus/Penicillium & 0.05 & 0.11 & $-0.19^{*}$ & 0.09 & 0.00 & -0.04 \\
\hline
\end{tabular}




\begin{tabular}{|l|r|r|r|r|r|r|}
\hline Chaetomium & 0.13 & 0.02 & 0.00 & -0.15 & $-0.19^{*}$ & 0.11 \\
\hline Cladosporium & $0.56^{*}$ & $0.25^{*}$ & $0.43^{*}$ & -0.08 & -0.08 & 0.13 \\
\hline Coprinaceae & 0.13 & $0.24^{*}$ & 0.08 & 0.16 & -0.01 & -0.09 \\
\hline Drechslera/Helminthosporium & $0.44^{*}$ & $0.23^{*}$ & $0.41^{*}$ & -0.09 & -0.09 & 0.05 \\
\hline Epicoccum & $0.33^{*}$ & 0.07 & $0.27^{*}$ & $-0.16^{*}$ & $-0.23^{*}$ & $0.20^{*}$ \\
\hline Ganoderma & $0.75^{*}$ & $0.34^{*}$ & $0.72^{*}$ & $-0.25^{*}$ & $-0.20^{*}$ & -0.03 \\
\hline Leptosphaeria & 0.03 & $0.27^{*}$ & -0.14 & $0.31^{*}$ & $0.42^{*}$ & -0.11 \\
\hline Myxomycota & 0.15 & 0.04 & 0.02 & 0.01 & 0.05 & -0.16 \\
\hline Oidium & $0.30^{*}$ & 0.04 & $0.20^{*}$ & $-0.18^{*}$ & -0.08 & 0.09 \\
\hline Pithomyces & $0.24^{*}$ & $0.17^{*}$ & -0.01 & 0.00 & -0.02 & 0.06 \\
\hline Pleospora & -0.07 & 0.10 & $-0.20^{*}$ & $0.19^{*}$ & $0.47 *$ & 0.08 \\
\hline Polythrincium & 0.05 & 0.11 & -0.02 & 0.10 & -0.04 & -0.11 \\
\hline Stemphyllium & $0.39^{*}$ & 0.03 & $0.24 *$ & $-0.16^{*}$ & -0.10 & 0.08 \\
\hline Thelephoraceae & -0.05 & 0.07 & -0.15 & 0.13 & -0.11 & 0.03 \\
\hline Torula & $0.39^{*}$ & $0.18^{*}$ & $0.22^{*}$ & -0.15 & $-0.18^{*}$ & 0.00 \\
\hline Ustilago & $0.39^{*}$ & $0.19^{*}$ & $0.57^{*}$ & $-0.25^{*}$ & -0.11 & 0.14 \\
\hline Xylariaceae & $0.49^{*}$ & $0.42^{*}$ & $0.25^{*}$ & 0.09 & 0.03 & $-0.19^{*}$ \\
\hline Other unicellular ascospores & $0.17^{*}$ & -0.03 & -0.01 & $0.42^{*}$ & $0.41^{*}$ & $-0.19^{*}$ \\
\hline Other bicellular ascospores & $0.25^{*}$ & $0.27^{*}$ & 0.08 & $0.39^{*}$ & $0.51^{*}$ & -0.14 \\
\hline Other pluricellular ascospores & $0.31^{*}$ & $0.47^{*}$ & 0.12 & $0.37^{*}$ & $0.50^{*}$ & -0.13 \\
\hline Other basidiospores & $0.53^{*}$ & $0.25^{*}$ & $0.53^{*}$ & $-0.26^{*}$ & -0.18 & 0.15 \\
\hline Total fungal spores & $\mathbf{0 . 5 4 *}$ & $\mathbf{0 . 2 7 *}$ & $\mathbf{0 . 1 8 *}$ & $\mathbf{0 . 3 0 *}$ & $\mathbf{0 . 3 2 *}$ & $-\mathbf{0 . 1 3}$ \\
\hline
\end{tabular}

\section{Relationship between fungal diseases in the tomato crop and airborne fungal spores}

Fig. 6 shows Oidium and Torula airborne spore dynamics recorded in the i-RTG during the study period. As expected, due to the fact that these fungal spore taxa are related to fungal diseases of tomato crops, indoor concentrations showed no relationship with concentrations outside of the greenhouse (Table 2). For this reason, information about the summer and winter cultivation periods were indicated in Fig. 6, as well as the initiation of leaf, flowering and fruiting stages, the winter and summer crop removal stages and some crop management practices. During the summer cultivation period, a total of 30 sweeps were made, and 29 pollinations were performed by hand (Fig. 6). Additionally, between the $18^{\text {th }}$ of April and the $17^{\text {th }}$ of June, 14 organic pesticide treatments were performed, using wettable sulphur and Costar (80\% Bacillus thuringiensis) (Fig. 6). However, it was not possible to eradicate the pest, and the treatments were only effective to avoid its expansion.

Overall, the number of fungal spores observed was higher for Oidium than Torula. Both fungal spore taxa showed similar behaviour during the summer cultivation period (Fig. 6). A total of 1,081 and 294 spores, respectively, were counted and identified in the indoor environment (Table 2). Most of the peaks occurred during the harvest period (Fig. 6).

Oidium was one of the most abundant taxa in the indoor environment ( $>1,000$ spores, Table 2$)$, and accounted for the highest indoor daily spore concentration on the $4^{\text {th }}$ of March 2016 at the 
time that the winter crop was removed, with 86.8 spores $/ \mathrm{m}^{3}$ (Fig. 6). In addition to the first peak of Oidium spore concentration, several episodes of peak concentrations have been detected during the leaf growth stage and the initiation of the flowering stage, accounting for 28.0 spores $/ \mathrm{m}^{3}$ on the $14^{\text {th }}$ of March 2016 and 30.8 spores $/ \mathrm{m}^{3}$ on the $29^{\text {th }}$ of March 2016. Additionally, high concentrations of Oidium spores were registered on the $19^{\text {th }}, 24^{\text {th }}, 27^{\text {th }}, 29^{\text {th }}$ and $31^{\text {st }}$ of May and the $2^{\text {nd }}$ of June 2016 during the tomato harvesting period, and these concentrations ranged between 19.6 and $39.2 \mathrm{spores} / \mathrm{m}^{3}$. Finally, the highest daily concentration of Oidium was detected on the $13^{\text {th }}$ of June 2016 during the summer crop, when 89.6 spores $/ \mathrm{m}^{3}$ were observed (Fig. 6). This date coincides with a day when pollination was done by hand and a sweep was done.

Regarding Torula, its highest spore concentration was measured on the $21^{\text {st }}$ of July 2016, with 39.2 spores $/ \mathrm{m}^{3}$ (Fig. 6). Moreover, three more peaks of $25.2,33.6$ and 22.4 spores $/ \mathrm{m}^{3}$ were measured on the $9^{\text {th }}, 15^{\text {th }}$ and $21^{\text {st }}$ of June 2016, all of them during the harvesting season (Fig. 6).

Figure 6. Torula and Oidium airborne fungal spore concentrations recorded in the i-RTG from the $24^{\text {th }}$ of February to the $28^{\text {th }}$ of April 2016. Summer and winter cultivation periods are shown, as well as the initiation of leaf growth, flowering and fruiting stages, the winter and summer crop removal (CR) stages and the three different ventilation modes. The visual detection of fungal infection by Oidium and the corresponding crop treatment are also indicated.

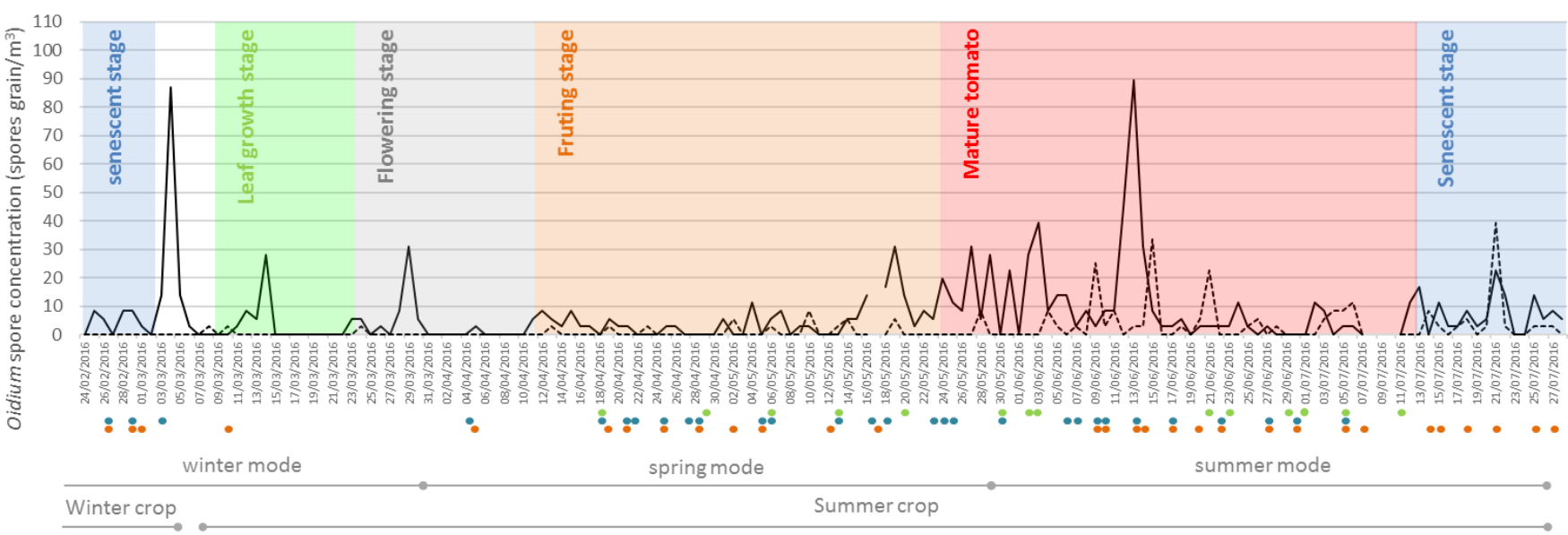

\section{Discussion}

516 The construction of RTGs on urban buildings has intensified in recent years, as a result of 517 growing interest in the development of new agricultural spaces and in the promotion of food 518 self-sufficiency in urban areas (Sanyé-Mengual et al., 2015). In greenhouses, the growth 519 conditions for plants are optimized to increase crop yields (Hansen et al., 2010). However, 520 indoor handling of large amounts of plant materials occurs in different occupational settings, 521 including greenhouses, and causes exposure to bioaerosols (Madsen et al., 2014). As indoor air 
is highly dynamic, studies have been carried out to examine indoor air quality, especially for occupational and public health purposes (Bonetta et al., 2010). Adequate assessment of human exposure to biological aerosols has been recognized as an important need, as many studies have linked adverse health effects to bioaerosol hazards (Burge and Rogers, 2000; Douwes et al., 2003). Fungal spores and pollen grains are the major components of airborne biological contaminants (Nayar and Jothish, 2013). They have the potential to trigger the risk of occupational respiratory diseases, such as allergic rhinitis, asthma, allergic alveolitis, dermatitis, hypersensitivity pneumonitis and bronchopulmonary aspergillosis (Cariñanos et al., 2004; Kim et al., 2007). In this study, we investigated the exposure to airborne pollen and fungal spores in an i-RTG in order to assess the biological air quality and to advise on preventive measures for workers and for users of the building in case the air is used to heat the building. It is appropriate to note that this is the first study that evaluates the diversity and dynamics of bioaerosols in building-integrated agriculture.

The pollen spectra collected both inside the i-RTG and in the outdoor environments are representative of the vegetation of the study area, in which Platanus and Pinus are the most abundant pollen taxa (Table 1). According to previous studies (Burge and Rogers, 2000; Lee et al., 2006; Tormo-Molina et al., 2009), the i/o ratios <1 and the significant positive correlations observed between indoor and outdoor pollen concentrations for most taxa (Table 1) indicate that the indoor pollen concentrations inside the i-RTG are controlled by those outdoors. Outdoor pollen entered the building through ventilation openings, except for Solanaceae pollen, which was directly introduced into the i-RTG via tomato plants. The level of pollen penetration depends on the aerobiological characteristics of the pollen and their pollination period (Pichot et al., 2015), as well as the distance to the ventilation opening (Jantunen and Saarinen, 2009). It has been recommended that allergic people reduce indoor exposure to pollen by keeping windows and doors closed during the peak flowering season, or by using appropriate air filters in ventilation windows and ducts (Jantunen and Saarinen, 2009). These measures could also be applied to i-RTG air that is to be recirculated into the building.

However, the recirculation of air from the i-RTG to other parts of the building is planned to occur during the winter, when the estimated pollen penetration was one hundred times lower than that in summer (Pichot et al., 2015). This fact is related to the increase of pollen penetration coefficients from winter to summer, which strongly supports the hypothesis that the opening of doors and windows facilitates the penetration of pollen into dwellings (Pichot et al., 2015). Moreover, outdoor pollen concentrations are lower in winter. Therefore, we focused our attention on indoor Solanaceae pollen concentrations. In particular, we considered that immunoglobulin E against tomato pollen has been detected in greenhouse workers (Toorenenbergen and Wijk, 2000). The highest Solanaceae daily pollen concentrations were recorded during both the winter and summer crop removal stages (Fig. 4). Consequently, our recommendation is that $\mathrm{i}$-RTG air should not be recirculated during crop removal unless appropriate air filters in ventilation ducts are installed.

Nearly $10 \%$ of people worldwide have a fungal allergy (Burge, 2001), in which the exposure to fungi is associated with rhinitis, asthma, allergic bronchopulmonary mycoses, allergic fungal sinusitis and hypersensitivity pneumonitis (Baxi et al., 2016). Although an official threshold for fungal spore concentrations necessary to evoke allergenic symptoms has been not established, the highest indoor daily concentration of total fungal spores observed in the i-RTG (26185 spores $/ \mathrm{m}^{3}$, Table 2) was lower than the concentration of $10^{5}$ spores $/ \mathrm{m}^{3}$ proposed by (Eduard, 
2009), but much higher than the concentration of $10^{3}$ spores $/ \mathrm{m}^{3}$ recommended by (Santilli and 568 Rockwell, 2003b).

569 In this study, the most prevalent i-RTG indoor fungal spore taxa were, in decreasing order, 570 Cladosporium (Fig. 5a), the group of other ascopores, Aspergillus/Penicillum, Ustilago, 571 Coprinaceae, Alternaria, Agrocybe and Oidium (>1,000 spores, Table 2), of which 572 Cladosporium, Aspergillus/Penicillium, Ustilago and Alternaria are classified as allergenic 573 fungi (Levetin et al., 2016). Cladosporium and Aspergillus/Penicillium were also identified as 574 predominant fungal species in other aeromycological studies carried out in other greenhouse 575 environments (Hansen et al., 2010; Li and Lamondia, 2010; Magyar et al., 2011). In addition, 576 sensitization to Cladosporium, Penicillium, Aspergillus, and/or Alternaria has been reported in 577 nearly $20 \%$ of greenhouse flower growers (Monsó et al., 2002). In this context, the daily 578 maximum concentration of Cladosporium $\left(4,449 \mathrm{spores} / \mathrm{m}^{3}\right)$ and Alternaria $\left(182 \mathrm{spores} / \mathrm{m}^{3}\right)$ in 579 the i-RTG exceeded both the fungal spore concentration thresholds recommended by Gravesen 580 (1979), namely 3,000 and 100 spores $/ \mathrm{m}^{3}$, respectively. The highest indoor concentration of 581 Aspergillus/Penicillum was $6,986 \mathrm{spores} / \mathrm{m}^{3}$ (Table 2). Although its threshold is unavailable, 582 this value is certainly able to provoke respiratory symptoms if we compare it with the much 583 lower outdoor values, which are known to cause problems for the population at large.

584 On the other hand, Cladosporium was identified as the most abundant outdoor fungal spore taxon (Table 2, Fig. 5a), as has been reported in previous studies performed in Catalonia (VélezPereira et al., 2016) and at other Iberian Peninsula locations (Oliveira et al., 2009; Recio et al., 2012; Reyes et al., 2016). Also, according to the outdoor fungal spore spectrum (Table 2), the airborne concentrations of Aspergillus/Penicillum, Coprinaceae, Ustilago, Alternaria and Pleospora were also notable in the study area, and have been noted by the previously cited authors at other Spanish localities (Herrero et al., 2006; Sabariego et al., 2000). For allergic people, indoor exposure to pollen and fungal spores is of particular concern (Nayar and Jothish, 2013). The $\mathrm{i} / \mathrm{o}_{\text {sum }}$ ratio showed that the outdoor concentrations were approximately double those of indoor areas in terms of total fungal spores (Table 2), and the outdoor concentrations were more than triple the indoor concentrations for pollen (Table 1). These results suggest that fungal spores have much higher penetration efficiency than pollen grains (Table 1), which reflects the difference in their particle sizes (Lee et al., 2006). In contrast, the fungal spore concentrations measured by stationary sampling in traditional heated tomato greenhouses reported higher values in indoor environments in Denmark (Hansen et al., 2010, 2012) and concentrations similar to those observed outdoors in Japan (Okushima et al., 2004). The i/o ratio for fungi observed in greenhouses where flowering plants are cultivated in the Midwestern USA in winter was also >1 (Adhikari et al., 2011). In this cases, the introduction of outside air into the greenhouses was recommended in order to dilute the indoor bioaerosol exposure (Madsen et al., 2014).

604 However, based on previous studies on indoor airborne fungi in buildings (Taekhee Lee et al., 2006b; Nevalainen et al., 2015), the $\mathrm{i} / \mathrm{o}_{\text {sum }}$ ratios $\leq 1$ and significant positive correlations registered for most of the fungal spore taxa in this study indicated that the most important source of fungi found indoors was the outdoor environment (Table 2). Within this group, the i/omax ratio was $\leq 1$ for Agrocybe, Coprinaceae, Ganoderma, Leptosphaeria, Pleospora, Stemphyllum, Thelephoraceae, Xylariaceae, other ascospores (unicellular, pluricellular), the total fungal spores during the whole period and during the spring ventilation mode (Table 2, Fig. 5a), which suggests that the indoor concentrations followed the outdoor concentrations, 
given that the outdoor levels were greater than the indoor ones (e.g., total fungal spores, Fig. 613 5a). On the other hand, the $\mathrm{i} / \mathrm{o}_{\max }$ ratio was $>1$ for Alternaria, Arthrinium, Cladosporium, 614 Ustilago, other bicelullar ascospores, and the total fungal spores during the winter and summer 615 ventilation modes (Table 2). These results suggest that, although fungal exposure primarily 616 occurred outdoors, fungi might have colonized the indoor environment under favourable 617 growing conditions after entering the i-RTG through ventilation openings, even reaching the 618 highest daily concentration in the indoor environment (e.g., Cladosporium, Fig. 5a). Since the 619 air penetration from the outdoor environment while the winter ventilation mode was in 620 operation was lower than for the other modes, highly favourable growing conditions in the i621 RTG during the winter ventilation period could explain this result. Indoor sources also played a 622 significant role in emitting fungal bioaerosols (Faridi et al., 2015) and displayed behaviour 623 independent of that seen outdoors, as indicated by the (1) $\mathrm{i} / \mathrm{o}_{\text {sum }}$ and $\mathrm{i} / \mathrm{o}_{\max }$ ratios $>1$ that were 624 observed for Aspergillus/Penicillum, Drechslera/Helminthosporium, Myxomycota, Pithomyces, 625 Torula and other basidiospores; and (2) the non-significant correlations obtained for Agaricus, 626 Aspergillus/Penicillium, Chaetomium, Epicoccum, Myxomycota, Oidium, Pithomyces, 627 Polythrincium and Torula (Table 2).

628 The most effective way to manage fungi in a building is to remove the conditions that favour the 629 establishment and growth of fungi (Haleem Khan and Mohan Karuppayil, 2012). From the point 630 of view of indoor air quality, prevention of any outdoor particles from entering the indoor 631 environment is considered desirable and can be done most effectively by combining an 632 optimized airflow together with filtration of outdoor air (Hänninen, O. and Asikainen, 2013). 633 Regular cleaning and disinfection of heating, ventilating and air conditioning systems should be 634 conducted to avoid the occurrence of air contamination (Liu et al., 2015). In this context, our 635 attention was focused mainly on understanding the dynamics of the fungal spores identified as 636 characteristic of indoor environments or capable of colonizing it.

637 Although indoor variables were controlled in the i-RTG in order to provide adequate conditions 638 for growing crops, the results showed that indoor temperature and relative humidity also 639 depended on outdoor environmental conditions, especially in the case of temperature (Table 3, 640 Fig. 5b). Different patterns have been observed between fungal spore taxa vs. indoor and 641 outdoor variables (Table 4). In the indoor environment, the daily concentrations of fungal spores 642 were positively and significantly correlated with indoor temperature, relative humidity or both 643 for the total of fungal spores and most taxa, except for Aspergillus/Penicillium, Chaetomium, 644 Myxomycota, Pleospora, Polythrincium and Theleforaceae, which displayed no correlation 645 (Table 3). Taking into account that Aspergillus/Penicillium, Chaetomium, Myxomycota and 646 Polythrincium showed their own dynamics indoors, further research is needed to understand 647 which variables determined the increases in fungal spores of these taxa, particularly 648 Aspergillus/Penicillium, which is one of the most abundant fungal taxa in the i-RTG (Table 2).

649 In the outdoor environment, the correlations between the daily concentrations of fungal spores 650 and the outdoor variables were variable, according to specific climatic requirements of each 651 taxon. In general, the relationship with temperature was positive for the total of fungal spores 652 and most of the fungal spore taxa; however, it was negative for Agrocybe, 653 Aspergillus/Penicillium and Pleospora (Table 3). Fungal spores are commonly described as 654 either "dry" or "wet," according to the type of weather associated with their occurrence in the 655 air. Ascospores generally follow precipitation, whereas spore types such as Alternaria and 656 Cladosporium are abundant in dry conditions (Troutt and Levetin, 2001). In keeping with the 

considering that they were negatively correlated with relative humidity and/or precipitation (Table 3). Otherwise, Agrocybe, Leptosphaeria, Pleospora and other ascospores (unicellular, bicellular, and pluricellular) were positively correlated with these variables and therefore correspond to the wet-spore type (Table 3). In addition, the total fungal spores were directly correlated with both relative humidity and precipitation (Table 3). This fact explains the substantial increases in the daily concentrations observed during and just after periods of rain (Fig. 5), which were largely produced by the massive proliferation of the group of other ascospores. Bearing in mind that the group of other ascospores was the second most abundant in both environments, in conjunction with the fact that the most important source of indoor spores was the outdoor environment (Table 2), our suggestion is to keep the ventilation openings in the i-RTG closed during rainy periods and for a few days after in order to avoid the entrance of fungal spores from the outdoors. Although the building under study has been programmed to close the ventilation openings during rainy periods, the time span of closure should be longer than just the time when the rain is falling, provided this measure does not affect crop development. This measure would enable us to avoid the increase of indoor fungal spore concentrations, because a smaller number of spores would be able to penetrate and colonize the indoor environment.

The behaviour of Torula and Oidium inside the i-RTG has been studied in detail, because these fungal spore taxa are related to fungal diseases of tomato crops (Fig. 6). Spores of both taxa were present in the greenhouses throughout the monitored period; however concentrations inside the i-RTG showed behaviour that was independent from that observed in the outside environment (Table 2). The results also suggest that agricultural management tasks, such as pollination by hand, fungal treatments and sweeps, increased the exposure to Torula and Oidium spores. Previous studies carried out in open-air field crops determined that powdery mildew spore (Oidium) release patterns are influenced by wind speed, rainfall, temperature, relative humidity and solar radiation (Byrne et al., 2000; Willocquet and Clerjeau, 1998; Willocquet et al., 1998). Conversely, the primary factor influencing the Oidium spore concentrations inside the i-RTG in this study was the indoor temperature (Table 3). Good temperature and humidity management are essential for minimizing disease, particularly for powdery mildew and Botrytis, in greenhouse crops (Gullino, 1992). Specifically, powdery mildew develops rapidly under dry conditions once infection occurs (Körner and Challa, 2003). This fact explains the development of Oidium disease in the tomato crop in our i-RTG (Fig. 6), which is characterized by higher ventilation and lower relative humidity than are typical in conventional greenhouses. Further research is needed to characterize the release patterns of the fungal spores in the case of the iRTG, given the special internal environmental (climate) conditions demanded by the building requirements.

Generally, concentrations of fungal spores registered for both taxa (Fig. 6) were in accordance with (Hansen et al., 2011) who suggested that vegetable growers' exposure to mesophilic fungi was found to be highest in environments where tomato plants were being removed, followed by environments in which tomatoes were harvested. However, unlike (Hansen et al., 2011), it was observed in this research that harvesting from mature plants caused higher spore concentration when plants dry out, the growth of Oidium and Torula stops (Fig. 6). However, an important fungal spore peak concentration was observed during the last days of the summer crop (Fig. 6). 
Previous studies showed that cleaning the aisles after leaf nipping resulted in a significantly higher exposure to endotoxin (Madsen et al., 2014). In this study, days when a sweep was performed did not always reflect an increase in the concentrations of Oidium or Torula spores (Fig. 6). Finally, the results showed that fungicide applications used were useful to treat powdery mildew. However, in accordance with (Wspanialy and Moussa, 2016), the infection was not eliminated because the treatment started during the last stage of the fungal disease.

\section{CONCLUSIONS}

710 To our knowledge, indoor bioaerosols have not previously been measured in building-integrated 711 agriculture facilities, and even less attention has been paid to urban rooftop greenhouses. In this study, elevated levels of pollen grains and fungal spores were observed in an i-RTG. These levels showed significant seasonal variations. A total of 4,924 pollen grains were observed inside the i-RTG during phase I of this study, which extended from the $24^{\text {th }}$ of February to the $10^{\text {th }}$ of April 2016, arriving at 334 pollen grains $/ \mathrm{m}^{3}$ per day, and a total of 295,038 fungal spores were observed during the whole sampling period, which extended from the $24^{\text {th }}$ of February to the $28^{\text {th }}$ of July 2016 , reaching a maximum daily concentration of $26,185 \mathrm{spores} / \mathrm{m}^{3}$. It is not possible to assess if these values are able to evoke allergenic symptoms, as an official threshold for fungal spore concentrations has not been established, and different authors have proposed different levels, such as $10^{5}$ spores $/ \mathrm{m}^{3}$ (Eduard, 2009) or $10^{3}$ spores $/ \mathrm{m}^{3}$ (Santilli and Rockwell 2003).

In this study, the most important source of indoor fungi was the outdoor environment ( $\mathrm{i} / \mathrm{o}_{\text {sum }}$ ratio showed that concentrations outdoors were approximately double those observed indoors). However, it should be noted that the sampling period coincided with the highest ventilation rates in the i-RTG. However, while the winter ventilation mode was in operation, the air penetration from the outdoor environment was lower than when the spring and summer modes were in operation. Consequently, the results suggested that highly favourable growing conditions occurred in the i-RTG during the winter. In the case of pollen dynamics, significant correlations were observed between indoor and outdoor pollen concentrations for most taxa. Our results suggest that fungal spores have a much higher penetration efficiency compared with pollen grains.

Solanaceae pollen and several fungal spore taxa, such the allergenic Aspergillus/Penicillium, were likely to have originated within the i-RTG, as indicated by the i/o ratios. Information on the qualitative and quantitative prevalence of airborne pollen grains and fungal spores is an important tool in the management of occupational allergic disorders in workers employed in the i-RTG and users of the building.

737 Meteorological conditions and agricultural management tasks that could cause high levels of pollen grains and fungal spores inside the i-RTG have also been identified. These results allow the identification of critical moments when the recirculation of residual i-RTG air is not appropriate, such as periods when crops are removed and when tomato plants are harvested; the Solanaceae pollen concentrations increased suddenly during these times. Our results suggest that Solanaceae pollen exposure could be significantly reduced by not drying out the tomato plants in the i-RTG. In addition, some i-RTG conditions and crop management tasks were related to the fluctuations in fungal spores associated with diseases of tomato crops (Oidium and 
been detected in the i-RTG Lab, which is characterized by higher ventilation and lower relative humidity than conventional greenhouses.

748 To conclude, it is possible to recirculate the air of the i-RTG to the building, and thus to convert the system into an Bi-RTG without posing health risks due to allergies for the building users if the biological air quality is monitored and the corresponding preventive measures are taken. To do so, the most important moments (which are related to the quality of the outdoor air, meteorological conditions and management practices) have to be identified. First, it is necessary to adapt the management of the i-RTG by controlling the opening and closing of the ventilation system. This measure can improve the air quality in the greenhouse for the workers during the summer. Second, when an Bi-RTG (that is, a building-greenhouse symbiosis system) has been installed to heat the building during the winter, it is necessary to identify times at which the residual air circulation should not take place. If it is not possible to stop the air injection, this study provides enough information to implement an appropriate air filter system that guarantees good air quality in the building spaces.

760

761

762

763

764

765

This study was carried out during the warm season, which coincides with the highest ventilation levels inside the i-RTG. As the recirculation of i-RTG air to buildings will be done during winter, further research is needed to elaborate the best strategy to avoid causing or aggravating allergies and breathing problems in the users of the building. Finally, it is necessary to establish internationally accepted occupational exposure limits for airborne fungi concentrations in greenhouses and in buildings.

\section{Acknowledgements}

The authors thank the Spanish Ministry of Economy and Competitiveness (MINECO) for the financial support of the research project "Agrourban sustainability through rooftop greenhouses. Eco-innovation on residual flows of energy, water and $\mathrm{CO}_{2}$ for food production" (CTM201347067-C2-1-R), the research project "Integrated rooftop greenhouses: energy, waste and $\mathrm{CO}_{2}$ symbiosis with the building. Towards foods security in a circular economy" (CTM201675772-C3-1-R; CTM2016-75772-C3-2-R; CTM2016-75772-C3-3-R) and the María de Maeztu program for Units of Excellence in R\&D (MDM-2015-0552).

The authors wish to express appreciation for the grants awarded to M. Ercilla-Montserrat by Generalitat de Catalunya (FI-DGR 2016).

The outdoor pollen and fungal spore measurements used in this study were provided by the Catalan Aerobiological Network (Xarxa Aerobiològica de Catalunya, XAC), a service run by the AEROBIOTA research group. The indoor pollen and fungal spore analyses were conducted at the same facility.

\section{REFERENCES}

[ACGIH] American Conference of Governmental Industrial Hygienists. 1999. Bioaerosols: assessment and control. American Conference of Governmental Industrial Hygienists; Cincinnati, Ohio.

Abdulla, H., Morshedy, H., Dewedar, A., 2008. Characterization of actinomycetes isolated from the indoor air of the church of Saint Katherine Monastery, Egypt. Aerobiologia (Bologna). 24, 35-41. doi:10.1007/s10453-007-9080-0

Adhikari, A., Gupta, J., Wilkins, J.R., Olds, R.L., Indugula, R., Cho, K.J., Li, C., Yermakov, 
M., 2011. Airborne microorganisms, endotoxin, and $(1 \rightarrow 3)-\beta$-D-glucan exposure in greenhouses and assessment of respiratory symptoms among workers. Ann. Occup. Hyg. 55, 272-285. doi:10.1093/annhyg/meq082

Agrios, G.N., 2005. Plant pathology. Elsevier Academic Press.

Altieri, M.A., Companioni, N., Cañizares, K., Murphy, C., Rosset, P., Bourque, M., Nicholls, C.I., 1999. The greening of the "barrios": Urban agriculture for food security in Cuba. Agric. Human Values 16, 131-140. doi:10.1023/A:1007545304561

Arny, C.J. (The O.S.U.W., Rowe, R.C., 1991. Effects of temperature and duration of surface wetness on spore production and infection of cucumbers by Didymella bryoniae. Phytopathol.

Bastl, K., Berger, U., Kmenta, M., 2016. Ten questions about pollen and symptom load and the need for indoor measurements in built environment. Build. Environ. 98, 200-208. doi:10.1016/j.buildenv.2016.01.006

Baxi, S.N., Portnoy, J.M., Larenas-Linnemann, D., Phipatanakul, W., Barnes, C., Grimes, C., Horner, W.E., Kennedy, K., Levetin, E., Miller, J.D., Scott, J., Williams, B., 2016. Exposure and Health Effects of Fungi on Humans. J. Allergy Clin. Immunol. Pract. 4, 396-404. doi:10.1016/j.jaip.2016.01.008

Bonetta, S., Bonetta, S., Mosso, S., Samp??, S., Carraro, E., 2010. Assessment of microbiological indoor air quality in an Italian office building equipped with an HVAC system. Environ. Monit. Assess. 161, 473-483. doi:10.1007/s10661-009-0761-8

Bornehag, C.G., Sundell, J., Bonini, S., Custovic, A., Malmberg, P., Skerfving, S., Sigsgaard, T., Verhoeff, A., 2004. Dampness in buildings as a risk factor for health effects, EUROEXPO: A multidisciplinary review of the literature (1998-2000) on dampness and mite exposure in buildings and health effects. Indoor Air 14, 243-257. doi:10.1111/j.16000668.2004.00240.x

Burge, H.A., 2001. Fungi: toxic killers or unavoidable nuisances? Ann. Allergy, Asthma Immunol. 87, 52-56. doi:10.1016/S1081-1206(10)62342-3

Burge, H.A., Rogers, C.A., 2000. Outdoor allergens. Environ. Health Perspect. 108, 653-659. doi:10.1289/ehp.00108s4653

Byrne, J.M., Hausbeck, M.K., Shaw, B.D., 2000. Factors Affecting Concentrations of Airborne Conidia of Oidium sp. Among Poinsettias in a Greenhouse. Plant Dis. 84, 1089-1095. doi:10.1094/PDIS.2000.84.10.1089

Cariñanos, P., Alcázar, P., Galán, C., Navarro, R., Domínguez, E., 2004. Aerobiology as a tool to help in episodes of occupational allergy in work places. J. Investig. Allergol. Clin. Immunol. 14, 300-8.

Cerón-Palma, I., 2012. Strategies for sustainable urban systems: introducing eco-innovation in buildings in Mexico and Spain. Universitat Autònoma de Barcelona.

Cerón-Palma, I., Sanyé-Mengual, E., Oliver-Solà, J., Montero, J.-I., Rieradevall, J., 2012. Barriers and opportunities regarding the implementation of Rooftop Eco.Greenhouses (RTEG) in Mediterranean cities of Europe. J. Urban Technol. 19, 1-17. doi:10.1080/10630732.2012.717685

D’Amato, G., Russo, M., Liccardi, G., Saggese, M., Gentili, M., Mistrello, G., D’Amato, M., Falagiani, P., 1996. Comparison between outdoor and indoor airborne allergenic activity. Ann. Allergy. Asthma Immunol. 77, 147-52. doi:10.1016/S1081-1206(10)63501-6

Dassonville, C., Demattei, C., Detaint, B., Barral, S., Bex-Capelle, V., Momas, I., 2008. Assessment and predictors determination of indoor airborne fungal concentrations in Paris newborn babies' homes. Environ. Res. 108, 80-85. doi:10.1016/j.envres.2008.04.006

Despommier, D., 2008. Cities dream of a second agricultural revolution. Sp. Mag. 488, $103-$ 105. 
Douwes, J., Thorne, P., Pearce, N., Heederik, D., 2003. Bioaerosol health effects and exposure assessment: Progress and prospects. Ann. Occup. Hyg. 47, 187-200. doi:10.1093/annhyg/meg032

Eduard, W., 2009. Fungal spores: a critical review of the toxicological and epidemiological evidence as a basis for occupational exposure limit setting, Crit Rev Toxicol. doi:10.3109/10408440903307333

Eduard, W., 2003. The Performance of Culture-Based Methods and Microscopy for Quantification of Noninfectious Airborne Microorganisms in Epidemiological Studies of Highly Contaminated Work Environments. AIHA J. 64, 684-689. doi:10.1080/15428110308984864

Elad, Y., Gullino, M.L., Shtienberg, D., Aloi, C., 1995. Managing Botrytis cinerea on tomatoes in greenhouses in the Mediterranean. Crop Prot. 14, 105-109. doi:10.1016/02612194(95)92863-I

Elad, Y., Malathrakis, N.E., Dik, A.J., 1996. Biological control of Botrytis-incited diseases and powdery mildews in greenhouse crops. Crop Prot. 15, 229-240. doi:10.1016/02612194(95)00129-8

FAO, 2011. World Agriculture: Towards 2015/2030. Summary Report.

Faridi, S., Hassanvand, M.S., Naddafi, K., Yunesian, M., Nabizadeh, R., Sowlat, M.H., Kashani, H., Gholampour, A., Niazi, S., Zare, A., Nazmara, S., Alimohammadi, M., 2015. Indoor/outdoor relationships of bioaerosol concentrations in a retirement home and a school dormitory. Environ. Sci. Pollut. Res. 22, 8190-8200. doi:10.1007/s11356-0143944-y

Flores, M.E.B., Medina, P.G., Camacho, S.P.D., de Jesús Uribe Beltrán, M., De la Cruz Otero, M. del C., Ramírez, I.O., Hernández, M.E.T., 2014. Fungal spore concentrations in indoor and outdoor air in university libraries, and their variations in response to changes in meteorological variables. Int. J. Environ. Health Res. 24, 320-40. doi:10.1080/09603123.2013.835029

Galán, C., Cariñanos, P., Alcázar, P., Domínguez, E., 2007. Spanish Aerobiology Network (REA): management and quality manual.

Galán, C., Smith, M., Thibaudon, M., Frenguelli, G., Oteros, J., Gehrig, R., Berger, U., Clot, B., Brandao, R., 2014. Pollen monitoring: minimum requirements and reproducibility of analysis. Aerobiologia (Bologna). 30, 385-395. doi:10.1007/s10453-014-9335-5

Ghosh, B., Lal, H., Kushwaha, R., Hazarika, N., Srivastava, A., Jain, V.K., n.d. Estimation of bioaerosol in indoor environment in the university library of Delhi 12222.

Gravesen, S., 1979. Fungi as a cause of allergic disease. Allergy Eur. J. Allergy Clin. Immunol. $34,135-154$.

Gullino, M.L., 1992. Integrated control of diseases in closed systems in the sub-tropics. Pestic. Sci. 36, 335-340. doi:10.1002/ps.2780360405

Haleem Khan, A.A., Mohan Karuppayil, S., 2012. Fungal pollution of indoor environments and its management. Saudi J. Biol. Sci. 19, 405-426. doi:10.1016/j.sjbs.2012.06.002

Hänninen, O. and Asikainen, A., 2013. Efficient reduction of indoor exposures. Health benefits from optimizing ventilation, filtration and indoor source controls. THL-Report, (National Institute for Health and Welfare).

Hansen, V.M., Meyling, N.V., Winding, A., Eilenberg, J., Madsen, A.M., 2011. Factors affecting vegetable growers' exposure to fungal bioaerosols and airborne dust. Ann. Occup. Hyg. 56, 170-181. doi:10.1093/annhyg/mer090

Hansen, V.M., Winding, A., Madsen, A.M., 2010. Exposure to bioaerosols during the growth season of tomatoes in an organic greenhouse using Supresivit (Trichoderma harzianum) and mycostop (Streptomyces griseoviridis). Appl. Environ. Microbiol. 76, 5874-5881. 
Herrero, A.D., Ruiz, S.S., Bustillo, M.G., Morales, P.C., 2006. Study of airborne fungal spores in Madrid, Spain. Aerobiologia (Bologna). 22, 135-142. doi:10.1007/s10453-006-9025-z

Hirst, J.M., 1952. An automatic volumetric spore trap. Ann. Appl. Biol. 39, 257-265.

Illing, H.P., 1997. Is working in greenhouses healthy? Evidence concerning the toxic risks that might affect greenhouse workers. Occup. Med. (Lond). 47, 281-93.

Immunology, E.A. of A. and C., 2015. More Europeans will be allergic to pollen if no measure is taken to reduce exposure Brussels,.

Jantunen, J., Saarinen, K., 2009. Intrusion of airborne pollen through open windows and doors. Aerobiologia (Bologna). 25, 193-201. doi:10.1007/s10453-009-9124-8

Jewett, T., Jarvis, W., Management, W.J., 2001. Management of the greenhouse microclimate in relation to disease control: a review of the greenhouse microclimate in rela- tion to disease control: a review 21, 351-366. doi:10.1051/agro:2001129>

Kim, K.-Y., Park, J.-B., Jang, G.-Y., Kim, C.-N., Lee, K.-J., 2007. Assessment of Bioaerosols in the Public Buildings of Korea. Indoor Built Environ. 16, 465-471. doi: $10.1177 / 1420326$ X07082534

Körner, O., Challa, H., 2003. Process-based humidity control regime for greenhouse crops. Comput. Electron. Agric. 39, 173-192. doi:10.1016/S0168-1699(03)00079-6

Lee, T., Grinshpun, S.A., Martuzevicius, D., Adhikari, A., Crawford, C.M., Reponen, T., 2006a. Culturability and concentration of indoor and outdoor airborne fungi in six single-family homes. Atmos. Environ. (1994). 40, 2902-2910. doi:10.1016/j.atmosenv.2006.01.011

Lee, T., Grinshpun, S.A., Martuzevicius, D., Adhikari, A., Crawford, C.M., Reponen, T., 2006b. Culturability and concentration of indoor and outdoor airborne fungi in six single-family homes. Atmos. Environ. 40, 2902-2910. doi:10.1016/j.atmosenv.2006.01.011

Levetin, E., Horner, W.E., Scott, J.A., Barnes, C., Baxi, S., Chew, G.L., Grimes, C., Kennedy, K., Larenas-Linnemann, D., Miller, J.D., Phipatanakul, W., Portnoy, J.M., Williams, P.B., 2016. Taxonomy of Allergenic Fungi. J. Allergy Clin. Immunol. Pract. 4, 375-385.e1. doi:10.1016/j.jaip.2015.10.012

Li, D.W., Lamondia, J., 2010. Airborne fungi associated with ornamental plant propagation in greenhouses. Aerobiologia (Bologna). 26, 15-28. doi:10.1007/s10453-009-9139-1

Liu, Z., Zhu, Z., Zhu, Y., Xu, W., Li, H., 2015. Investigation of dust loading and culturable microorganisms of HVAC systems in 24 office buildings in Beijing. Energy Build. 103, 166-174. doi:10.1016/j.enbuild.2015.06.056

Madsen, A.M., Tendal, K., Frederiksen, M.W., 2014. Attempts to reduce exposure to fungi, $\beta$ glucan, bacteria, endotoxin and dust in vegetable greenhouses and a packaging unit. Sci. Total Environ. 468, 1112-1121. doi:10.1016/j.scitotenv.2013.09.014

Magyar, D., Eszéki, E.R., Oros, G., Szécsi, Á., Kredics, L., Hatvani, L., Körmöczi, P., 2011. The air spora of an orchid greenhouse. Aerobiologia (Bologna). 27, 121-134. doi:10.1007/s10453-010-9182-y

Malling, H.J., Dreborg, S., Weeke, B., 1986. Diagnosis and immunotherapy of mould allergy. V. Clinical efficacy and side effects of immunotherapy with Cladosporium herbarum. Allergy 41, 507-19.

Monsó, E., Magarolas, R., Badorrey, I., Radon, K., Nowak, D., Morera, J., 2002. Occupational asthma in greenhouse flower and ornamental plant growers. Am. J. Respir. Crit. Care Med. 165, 954-960. doi:10.1164/ajrccm.165.7.2106152

Montero, J., Stanghellini, C., Castilla, N., 2009. Greenhouse technology for sustainable production in mild winter climate areas: trends and needs, in: Tüzel, Y., Öztekin, G., Meric, M. (Eds.), Proceedings of International Symposium on Strategies Towards 
Sustainability of Protected Cultivation in Mild Winter Climate. Antalya, Turkey.

Nadal, A., Llorach-Massana, P., Cuerva, E., López-Capel, E., Montero, J.I., Josa, A., Rieradevall, J., Royapoor, M., 2017. Building-integrated rooftop greenhouses: An energy and environmental assessment in the mediterranean context. Appl. Energy 187, 338-351. doi:10.1016/j.apenergy.2016.11.051

Nayar, T.S., Jothish, P.S., 2013. An assessment of the air quality in indoor and outdoor air with reference to fungal spores and pollen grains in four working environments in Kerala, India. Aerobiologia (Bologna). 29, 131-152. doi:10.1007/s10453-012-9269-8

Nevalainen, A., Täubel, M., Hyvärinen, A., 2015. Indoor fungi: Companions and contaminants. Indoor Air 25, 125-156. doi:10.1111/ina.12182

Okushima, L., Ishii, M., Sase, S., Saito, M., Ikeguchi, A., 2004. An evaluation of floating dust particles and molds in commercial greenhouses. Acta Hortic. 639, 359-366.

Oliveira, M., Ribeiro, H., Delgado, J.L., Abreu, I., 2009. Seasonal and intradiurnal variation of allergenic fungal spores in urban and rural areas of the North of Portugal. Aerobiologia (Bologna). 25, 85-98. doi:10.1007/s10453-009-9112-z

Pichot, C., Calleja, M., Penel, V., Bues-Charbit, M., Charpin, D., 2015. Inference of the pollen penetration and remanence into dwellings using seasonal variation of indoor/outdoor pollen counts. Aerobiologia (Bologna). 31, 315-322. doi:10.1007/s10453-015-9366-6

Recio, M., del Mar Trigo, M., Docampo, S., Melgar, M., García-Sánchez, J., Bootello, L., Cabezudo, B., 2012. Analysis of the predicting variables for daily and weekly fluctuations of two airborne fungal spores: Alternaria and Cladosporium. Int. J. Biometeorol. 56, 983991. doi:10.1007/s00484-011-0509-3

Reyes, E.S., de la Cruz, D.R., Sánchez, J.S., 2016. First fungal spore calendar of the middlewest of the Iberian Peninsula. Aerobiologia (Bologna). 32, 529-539. doi:10.1007/s10453016-9430-x

Sabariego, S., Díaz de la Guardia, C., Alba, F., 2000. The effect of meteorological factors on the daily variation of airborne fungal spores in Granada (southern Spain). Int. J. Biometeorol. 44, 1-5. doi:10.1007/s004840050131

Santilli, J., Rockwell, W., 2003a. Fungal contamination of elementary schools: a new environmental hazard. Ann. Allergy, Asthma Immunol. 90, 203-208. doi:10.1016/S10811206(10)62142-4

Santilli, J., Rockwell, W., 2003b. Fungal contamination of elementary schools: a new environmental hazard. Ann. Allergy. Asthma Immunol. 90, 203-8. doi:10.1016/S10811206(10)62142-4

Sanyé-Mengual, E., Cerón-Palma, I., Oliver-Solà, J., Montero, J., Rieradevall, J., 2013. Environmental analysis of the logistics of agricultural products from roof top greenhouses in Mediterranean urban areas. J. Sci. Food Agric. 93, 100-109. doi:10.1002/jsfa.5736

Sanyé-Mengual, E., Oliver-Solà, J., Montero, J.I., Rieradevall, J., 2015. An environmental and economic life cycle assessment of rooftop greenhouse (RTG) implementation in Barcelona, Spain. Assessing new forms of urban agriculture from the greenhouse structure to the final product level. Int. J. Life Cycle Assess. doi:10.1007/s11367-014-0836-9

Shelton, B.G., Kirkland, K.H., Flanders, W.D., Morris, G.K., 2002. Profiles of Airborne Fungi in Buildings and Outdoor Environments in the United States. Appl. Environ. Microbiol. 68, 1743-1753. doi:10.1128/AEM.68.4.1743-1753.2002

Specht, K., Siebert, R., Hartmann, I., Freisinger, U.B., Sawicka, M., Werner, A., Thomaier, S., Henckel, D., Walk, H., Dierich, A., 2014. Urban agriculture of the future: an overview of sustainability aspects of food production in and on buildings. Agric. Human Values 31, 33-51. doi:10.1007/s10460-013-9448-4

Strachan, D.P., 1988. Damp housing and childhood asthma: validation of reporting of 
symptoms. BMJ 297, 1223-6.

984

985

986

987

988

989

990

991

992

993

994

995

996

997

998

999

1000

1001

1002

1003

1004

1005

1006

1007

1008

1009

1010

1011

1012
Swan, J.R., Crook, B., 1998. Airborne microorganisms associated with grain handling. Ann. Agric. Environ. Med. 5, 7-15.

Toorenenbergen, A.W. Van, Wijk, R.G. Van, 2000. Immunoblot Analysis of IgE-Binding Antigens in Paprika and Tomato Pollen.

Tormo-Molina, R., Gonzalo-Garijo, Á., Silva-Palacios, I., Fernández-Rodríguez, S., 2009. Seasonal and spatial variations of indoor pollen in a hospital. Int. J. Environ. Res. Public Health 6, 3169-3178. doi:10.3390/ijerph6123169

Troutt, C., Levetin, E., 2001. Correlation of spring spore concentrations and meteorological conditions in Tulsa, Oklahoma. Int. J. Biometeorol. 45, 64-74. doi:10.1007/s004840100087

Vélez-Pereira, A.M., De Linares, C., Delgado, R., Belmonte, J., 2016. Temporal trends of the airborne fungal spores in Catalonia (NE Spain), 1995-2013. Aerobiologia (Bologna). 32, 23-37. doi:10.1007/s10453-015-9410-6

Verhaar, M.., 1998. Studies on biological control of powdery mildew in cucumber (Sphaerotheca fuliginea) and rose (S. pannosa) by means of mycoparasites. Wageningen University.

Willocquet, L., Berud, F., Raoux, L., Clerjeau, M., 1998. Effects of wind, relative humidity, leaf movement and colony age on dispersal of conidia of Uncinula necator, causal agent of grape powdery mildew. Plant Pathol. 47, 234-242. doi:10.1046/j.1365-3059.1998.00242.x

Willocquet, L., Clerjeau, M., 1998. An analysis of the effects of environmental factors on conidial dispersal of Uncinula necator (grape powdery mildew) in vineyards. Plant Pathol. 47, 227-233. doi:10.1046/j.1365-3059.1998.00244.x

Wspanialy, P., Moussa, M., 2016. Early powdery mildew detection system for application in greenhouse automation. Comput. Electron. Agric. 127, 487-494. doi:10.1016/j.compag.2016.06.027

Yelle, S., Beeson, R.C., Trudel, M.J., Gosselin, A., 1990. Duration of CO2 Enrichment Influences Growth, Yield, and Gas Exchange of Two Tomato Species. J. Am. Soc. Hortic. Sci. $115,52-57$. 